\title{
Gas rising through a large diameter column of very viscous liquid: flow patterns and their dynamic characteristics
}

\author{
Abbas H. Hasan ${ }^{1}$, Shara K Mohammed ${ }^{2,3}$, Laura Pioli ${ }^{4,5}$, Buddhika N. \\ Hewakandamby $^{2}$, Barry J. Azzopardi ${ }^{2}$ \\ Faculty of Engineering, University of Hull, UK \\ Faculty of Engineering, University of Nottingham, Nottingham NG7 2RD, UK \\ Erbil Technology Institute, Erbil Polytechnic University, Kurdistan region -Iraq \\ Département des Sciences de la Terre, Université de Genève, Switzerland \\ Department of Chemical and Geological Sciences, University of Cagliari- Italy
}

Gas-liquid flows are affected strongly by both the liquid and gas properties and the pipe diameter, which control features and the stability of flow patterns and their transitions. For this reason, empirical models describing the flow dynamics can be applied only to limited range of conditions. Experiments were carried out to study the behaviour of air passing through silicone oil (360 Pa.s) in $240 \mathrm{~mm}$ diameter bubble column using Electrical Capacitance Tomography and pressure transducers mounted on the wall. These experiments are aimed at reproducing expected conditions for flows including (but not limited to) crude oils, bitumen, and magmatic flows in volcanic conduits. The paper presents observation and quantification of the flow patterns present. It particularly provides the characteristics of gas-liquid slug flows such as: void fraction; Taylor bubble velocity; frequency of periodic structures; lengths of liquid slugs and Taylor bubbles. An additional flow pattern, churn flow, has been identified. The transition between slug and churn has been quantified and the mechanism causing it are elucidated with the assistance of a model for the draining of the liquid film surrounding the Taylor bubble once this has burst through the top surface of the aerated column of gas-liquid mixture. It is noted that the transition from slug to churn is gradual.

\section{Keywords:}

flow patterns; high viscous liquid; bubbly to slug and slug to churn transition; large pipe diameter; Electrical Capacitance Tomography

(C2019, Elsevier. This manuscript version is made available under the CC-BY-NC-ND 4.0 license http://creativecommons.org/licenses/by-nc-nd/4.0/ 


\section{Introduction}

The flow in many pieces of equipment from the hydrocarbon production, power generation and chemical industries such as heat exchangers, chemical reactors, pipelines, distillation and absorption columns, phase separators and the pipes connecting them as well as natural systems such as volcanoes, involve gas/liquid flows. An understanding of the flow dynamics is vital for the design of safe and environmentally friendly equipment, as well as for its construction at minimum capital cost and for its efficient operation as well as for hazard quantification in the natural environment (Azzopardi, 2006)

The majority of studies on gas/liquid flows have been carried out with liquids with viscosities around that of water at ambient conditions and within small diameter (i.e. $<70 \mathrm{~mm}$ ) columns (Azzopardi, 2006). For those, the steady state and dynamic behaviour of the flow is usually described through flow patterns, descriptions which cover reasonable ranges of flow rates. In vertical pipes, these are usually identified as: bubbly; slug; churn and annular. As its name implies, bubbly flow consists of separate bubbles dispersed within a liquid continuum. As the gas flow rate increases, so does the concentration and packing of the bubbles. Consequently, the bubbles coalesce and grow in size. In pipes with diameters larger than 100 $\mathrm{mm}$, spherical cap bubbles can be formed and in both larger and smaller diameter pipes, the bubble size reaches nearly the pipe diameter. It is observed that depending on the viscosity of the continuous phase, bullet shaped bubbles could be formed. The flow is now called slug flow and the liquid slugs are interspersed between the large bubbles. The slugs can contain significant quantities of small bubbles in them. Further increase in gas flow rate results in, first the churn flow and then the annular flow where the liquid is divided between a wall film and droplets which are atomised from disturbance waves travelling on the film interface and subsequently redeposit on to the film. The volume fraction of the liquid flowing as drops can vary from 0 to nearly 1 . 
However, the dynamics of gas-liquid flows is affected strongly by both the liquid and gas properties and the pipe diameter; more specifically, not only the specific features and the stability of bubbly, slug, churn and annular flow are expected to be significantly different, but also the mechanisms controlling their transitions.

For example, Shah et al. (1982) noted that slug flow in the classic form described here does not occur in larger diameter pipes; no slug flow is predicted in water-air flow, in pipes or columns with diameters larger than $100 \mathrm{~mm}$ because of instability of the liquid/gas interface. Sharaf et al. (2016) reported that the gas volume fraction of the pipe cross-section in the large bubble and liquid slug parts of the flow approach the same value and these two parts become indistinguishable using void fraction measurements. Further increase in the gas velocity causes slug flow to break down to a flow which can involve vertically oscillating or churning motion, churn flow. Mori et al. (1996) identified huge waves on the film interface as the characterising feature of churn flow. Sharaf et al. (2016) showed that there could be large structures present in the gas core of churn flow and attributed these to being incomplete atomisation of liquid from the wall film.

For low viscosity liquids, the transition between slug and churn flows is associated with the phenomenon of flooding, or counter-current flow limitation, of the liquid surrounding the Taylor bubbles in slug flow. Flooding has been studied by introducing a liquid film part way up a pipe and passing a gas upwards (Govan et al., 1991). Increasing the velocity of the gas causes large amplitude waves on the film interface. At a critical gas flow rate, the liquid film is held up. Any subsequent increase of the gas flow rate results in upward flow of the liquid. The most revealing experiments, by McQuillan et al. (1985), show that the holding up process occurs by one wave being brought to a standstill. Subsequent waves are not sheltered and flow into the stationary wave causing its amplitude to increase. The several studies on this topic, which have been reviewed by Azzopardi (2006), show that below a pipe diameter of $\sim 70 \mathrm{~mm}$ 
the critical gas velocity depends on the liquid (down) flow rate, the pipe diameter and the physical properties of the liquid (density, viscosity and surface tension). It can also depend on the arrangements for introducing and exiting of the liquid. Some of these might encourage the premature formation and growth of waves and hence the critical gas velocity will be lower than otherwise. A number of (usually empirical) equations have been proposed for the critical or flooding velocity. From testing against banks of experimental data, the ones proposed by McQuillan and Whalley (1985) and (Zapke and Kröger, 2000) emerged as the most accurate.

Though most of the models developed for flow pattern transitions are deterministic, i.e., they assume the transition occurs at very specific conditions. However, there is increasing evidence that there can be broad transition regions where the characteristic structures for more than one flow pattern can co-exist. This is exemplified in the results of experiments by Mori et al. (1996) who studied air-water in a $25.8 \mathrm{~mm}$ diameter pipe. An example at a liquid superficial velocity $=0.1 \mathrm{~m} / \mathrm{s}$ is illustrated in Figure 1.

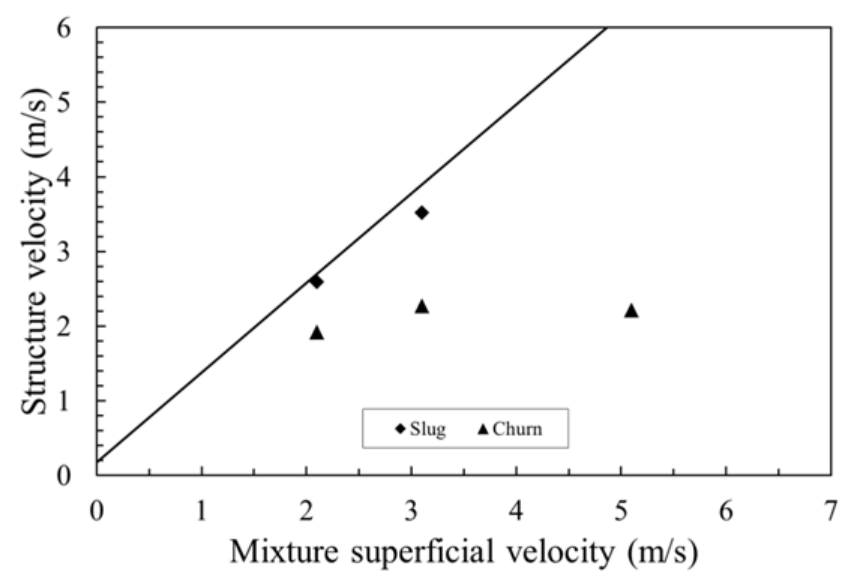

Figure 1: Structure velocities for slug and churn flow measured by Mori et al. (1996) for air-water in a $25.8 \mathrm{~mm}$ diameter pipe. Liquid superficial velocity $=0.1 \mathrm{~m} / \mathrm{s}$. Line shows values from equation (4.4) with $\mathrm{CO}=1.2$ and $\mathrm{Fr}=0.35$.

Where there is no net liquid flow, as in bubble columns, flow patterns are also invoked in describing the flow. For liquid with properties close to water, the graphical delineation proposed by Shah et al. (1982) in the form of a plot of gas superficial velocity against column 
diameter, identifies three patterns, homogeneous flow, slug flow and heterogeneous flow. The last is also called churn-turbulent flow.

In addition, the more limited work on pipes $>70 \mathrm{~mm}$ shows that the flooding velocity is independent of pipe diameter. However, the experiments in this area are almost exclusively based on water.

Little information is available in the literature about the behaviour of gas/high viscous liquid flows. This requires rectification for two reasons. The first is that the more of the oils being extracted from the ground and processed are now, what is termed, heavy oils, i.e., of higher viscosity. Values of 3 to >1000 Pa.s for Orinoco belt crude oils, and $2000 \mathrm{~Pa}$.s for Athabasca bitumen, have been reported by (Chirinos et al., 1983) and Shu (1984), respectively. The second arises from the natural environment, specifically in volcanoes. Silicatic magmas rise in volcanic conduits as multiphase flow mixtures of silica-rich liquid, crystals and gas. The surface tension of the liquid is $\sim 0.08 \mathrm{~N} / \mathrm{m}$ (Gardner et al., 2013) and the viscosity varies with their chemical composition (mostly silica and water content in the range $10^{1}-10^{9}$ Pa.s, (Giordano et al., 2008). The explosivity and style of volcanic eruptions depend, fundamentally, on magma rheology, gas content and flow dynamics within the volcanic conduit. Conditions for separated two-phase flow are met in low viscosity magmas, i.e., viscosities comprised between 10 to $10^{3} \mathrm{~Pa} \mathrm{~s}$, where gas bubbles rise controls magma outgassing and mild-explosivity (i.e., Hawaiian, Strombolian) eruptive styles. The knowledge of conduit flow dynamics and conditions required for flow pattern stability are fundamental for the correct interpretation of geophysical (seismic, thermal and geochemical) monitoring data, quantification and forecasting of eruptions and studies of volcanic hazard.

The aim of the work presented in this paper is to study and quantify the behaviour and characteristics of gas-liquid flows through a large diameter $(240 \mathrm{~mm})$ bubble column using a 
very viscous liquid. These experiments are designed and conducted to improve our knowledge on flow pattern stability in vertical gas- liquid flows as the liquid has a very high viscosity. The viscosity of the liquid (silicone oil) is in fact $360 \mathrm{~Pa} \mathrm{~s}$, two orders of magnitude larger than the highest viscosity liquid employed in constructing empirical equations describing flow pattern transitions. The experiments quantify and monitor the flow structures for a large range of gas superficial velocity, $u_{g s}$ with the aim of identifying the flow patterns, their characteristics, stability and transition mechanisms.

\section{Experimental arrangements}

Experiments were carried out in a flow facility that consists of a $240 \mathrm{~mm}$ inner diameter, 7.6 $\mathrm{m}$ long vertical column, which is made mainly of acrylic pipe. The first $0.6 \mathrm{~m}$ is made of steel whilst the section where the Electrical Capacitance Tomographic (ECT) probe is mounted is made of PVC. The ECT probe is mounted $3.06 \mathrm{~m}$ above the gas injection point which is equivalent to $12 \mathrm{D}$. This is a fairly sufficient length for fully developed flow in such viscous oil. There is no published work, up to date, that address the flow development in high viscous oil (>100 Pa.s). Mohammed, S. K. (2017) who studied the behaviour of silicone oil (360 Pa.s) in a gas bubble column (using the same facilities and dimensions used in the current study) and found that the bubble velocity measured upstream the ECT by a high speed camera was in good agreement with that measured by an ECT (where the maximum error was $1.2 \%$ ). Ibrahim et al. (2018) who investigated flow development of four different silicone oil viscosities (ranged from $4 \mathrm{cP}$ to $104.6 \mathrm{cP}$ ) found that the flow develops faster with increasing liquid viscosity. They showed that at high void fraction $(>0.6)$, the mean void fraction of a silicone oil (with a viscosity above $25.4 \mathrm{cp}$ ) measured at two different axial locations (15D and 62D) are in good agreement. The position of the ECT probes, the pressure transducers and the thermocouple are shown in Figure 2. 


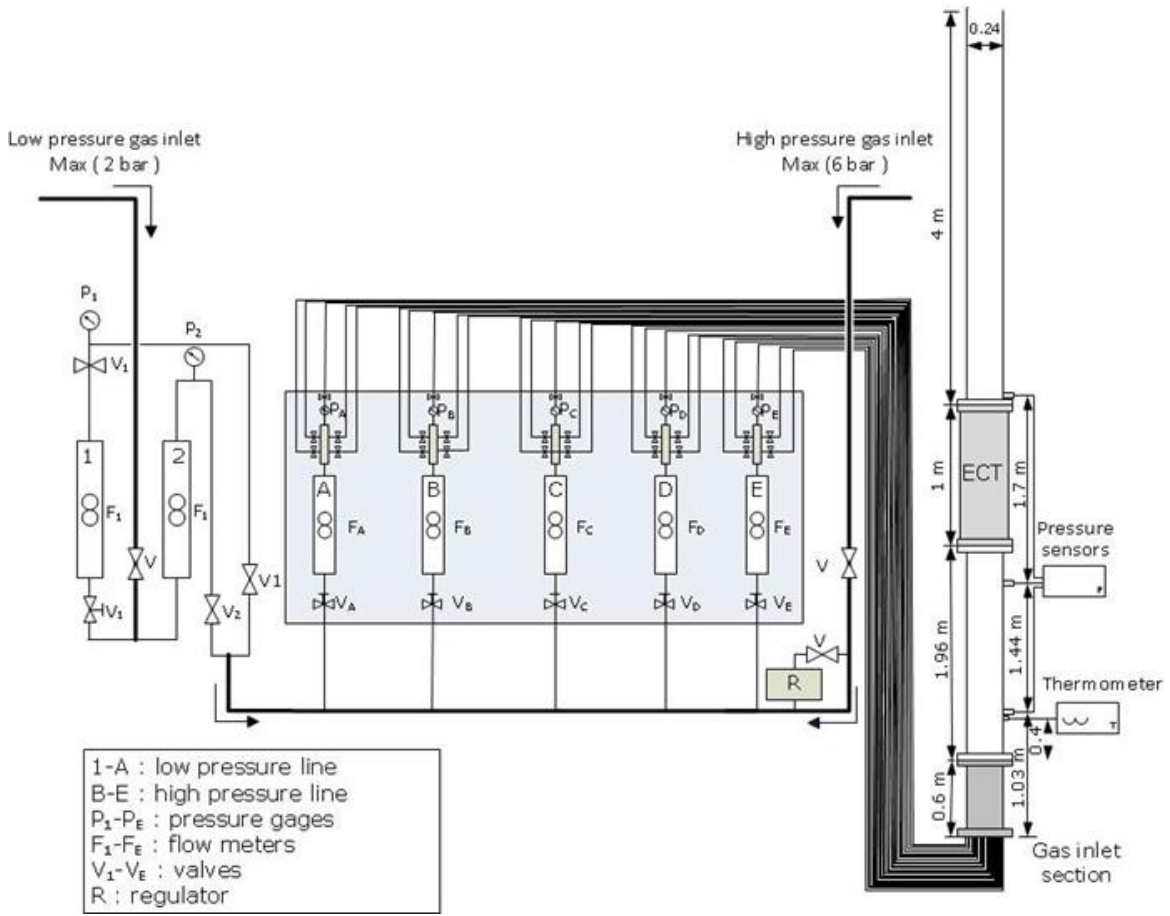

Figure 2: Details of column employed in this work showing positions of instruments and method of gas injection

The compressed air from the laboratory compressor (at 6 bar) is divided into 5 lines that are metered using variable area flow meters. A manifold with five tube connections is fitted to the outlet of each flow meter. The tubes then feed the 25 nozzles mounted at the bottom of the vertical pipe section. This arrangement allows the control of flow through each nozzle while allowing a reasonably accurate measurement of the flow rate especially when a fewer number of nozzles are in operation. In the experiments reported here, the column was filled to an initial liquid height of $3.27 \mathrm{~m}$.

Absolute pressure was monitored using three sealed gauge pressure transmitters installed along the column at 1.02, 2.47 and $4.17 \mathrm{~m}$ from the air injection point. These had sensitivities of $0.1,0.1$ and 0.02 bar/volt respectively. They were sampled via a LabView programme at frequencies of $50 \mathrm{~Hz}$. Reference pressures for each were determined when the column was initially filled with oil. In some of the runs the top transmitter was above the static liquid level and therefore at atmospheric pressure, the pressures for the other two were obtained from the height of liquid above them. 
The main measurement instrument employed in this work is a twin-plane Electrical Capacitance Tomography (ECT) sensor. ECT is a non-intrusive technique which provides phase distribution, velocity measurements and phase volume fraction in a conduit containing non-conducting materials. The technique has the capability to capture the data up to 5000 frames per second. The equipment consists of a sensor, a data acquisition unit (TFL R5000) and a computer for data storage and image reconstruction. For the experiments presented in this paper, twin plane, 8 electrode sensors (with inter-plane spacing of $36 \mathrm{~mm}$ ) were used to capture data at different gas superficial velocities. An array of electrodes was arranged around the outside of the non-conducting pipe wall and all unique capacitance pairs were measured using a TFL-R5000 flow imaging and analysis system. The TFLR5000 Capacitance Measurement Unit (CMU) contains 16 (i.e. twin, 8 electrodes) identical measurement channels and 16 identical driven guard channels. In the experiments reported here the frame rate was typically $50 \mathrm{~Hz}$. An excitation signal was used in the form of a $15 \mathrm{~V}$ peak to peak square wave with a frequency of $1 \mathrm{MHz}$. For more details on how the measured capacitances from ECT electrodes are converted into the permittivity (or concentration) distribution, see for example, (Byars, 2001). The validation of the ECT technique is described in more details by Mohammed et al. (2018).

The physical properties of the silicone oil were used in the present work are; density $=$ $950 \mathrm{~kg} / \mathrm{m}^{3} ;$ viscosity $=360$ Pa.s; surface tension $=0.02 \mathrm{~N} / \mathrm{m}$. The viscosity of the silicone oil used in the current study was also verified under the bench test by exerting a specific shear rates using a viscometer with a rotating spindle. It was found that, the oil viscosity was independent of the applied shear force and it was changed only with temperature, (Papanastasiou et al., 1999). 30 experiments were conducted with the ECT at gas superficial velocities in the range of $0.003-0.223 \mathrm{~m} / \mathrm{s}$. A separate campaign, in which the pressure 
measurements were made, involved 10 gas flow rates with gas superficial velocities in the range of $0.0008-0.43 \mathrm{~m} / \mathrm{s}$.

\section{Results}

\subsection{Flow regimes}

The time series of void fraction for silicone oil at different gas superficial velocities is shown in Figure 3. These data can also be examined via the Probability Density Function (PDF), Figure 5, which presents the fractional number of times that each void fraction occurs. Khatib and Richardson (1984) and Costigan and Whalley (1997) showed that the PDF of the crosssectional averaged void fraction time series for slug flow can be characterised by two peaks as shown in Figure 5.

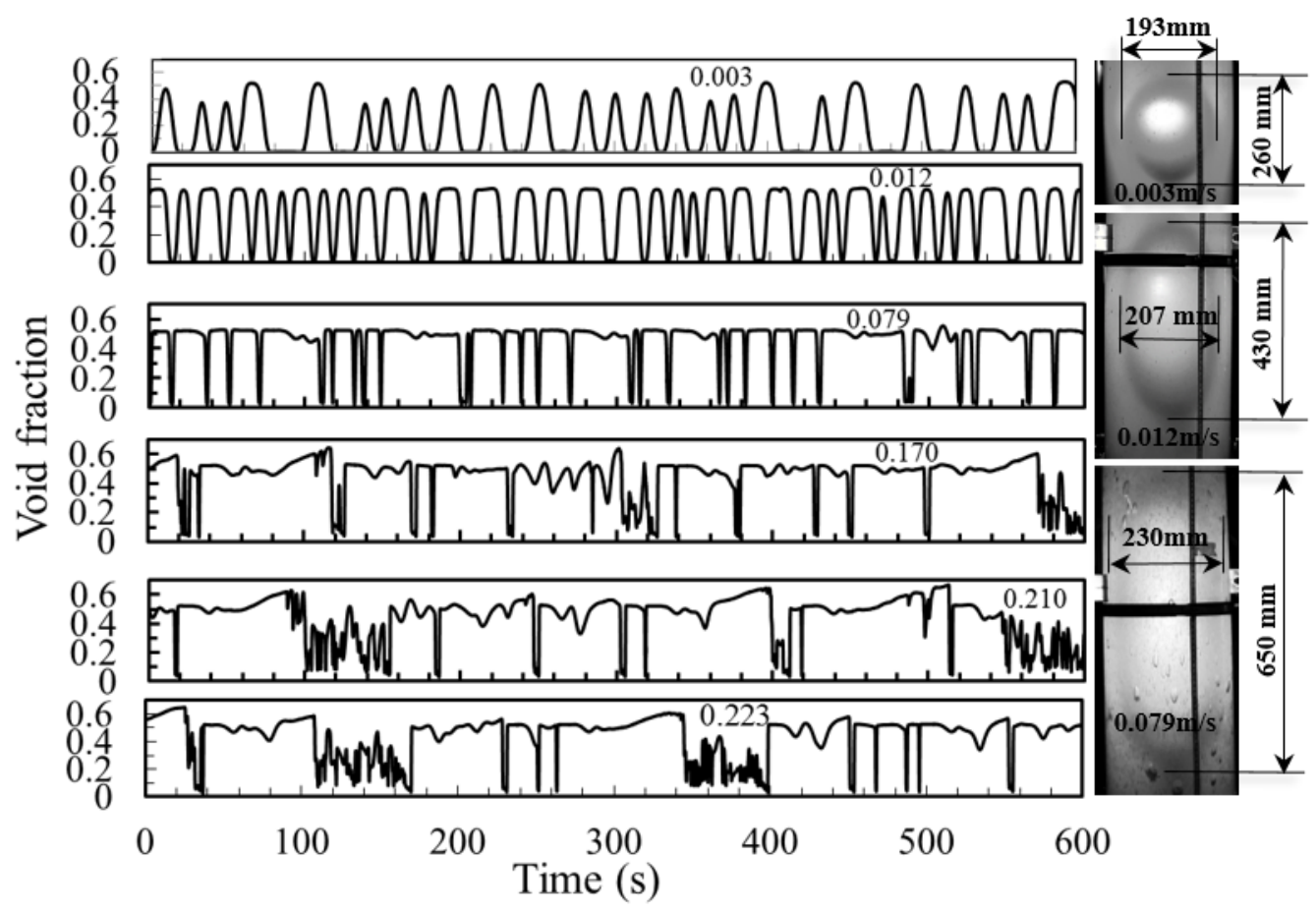

Figure 3: Time series of void fraction for silicone oil-air experiments. Numbers refer to gas superficial velocity $(\mathrm{m} / \mathrm{s})$. Photos (right) are for the large bubbles rising upward in the column at different gas superficial velocities.

It is seen from Figure 3 that at a low gas superficial velocity $(0.003 \mathrm{~m} / \mathrm{s})$ regular large bubbles with a range of sizes were formed. It should be mentioned that at low gas flow 
rates (i.e. bubbly flow), the visual observation showed that the bubbles are large and spherical. When the gas flow rates increased, bubbles become smaller and the liquid becomes milky which obscures the vision of the naked eyes. Their existence can be inferred in the corresponding PDF, Figure 5, with a strong peak at low void fractions, the liquid regions between bubbles, together with a broad peak at higher void fractions - the breadth being a product of the range of bubble sizes. If the gas superficial velocity is increased to $0.012 \mathrm{~m} / \mathrm{s}$, more elongated ellipsoidal bubbles were formed', i.e., slug flow. The abrupt decrease and increase of void fraction seen at the passage of the Taylor bubbles suggest that they changed in shape getting flatter base and top. The PDF (see Figure 5) now has the stronger peak at the higher void fraction. Further increase of gas superficial velocity to $0.079 \mathrm{~m} / \mathrm{s}$ results in fewer, longer bubbles and shorter, intervening, liquid slugs. There is evidence of coalescence of Taylor bubbles, i.e., at $\sim 200$ and 310 seconds (Figure 3, at $u_{g s}=0.079 \mathrm{~m} / \mathrm{s}$ ). The corresponding PDF shows an even more pronounced peak at higher void fractions. The peak at low void fractions can be seen to be moving away from the liquid-only value of 0.0 . This is due to accumulation of $\mu \mathrm{m}-\mathrm{mm}$ sized bubbles which are mainly created by the bursting of Taylor bubbles at the top surface of the aerated column and which, because of their small size combined with the high viscosity of the liquid, are accumulated throughout the runs at successively increasing gas velocity (see the photo in Figure 3 at ugs $=0.079 \mathrm{~m} / \mathrm{s}$, where small bubbles are clearly present). Also important here are the longer periods for which the ECT is seeing high void fraction, e.g., for a gas superficial velocity of $0.223 \mathrm{~m} / \mathrm{s}$ these are, approximately, at 40-109, 170-230, 269-340, 400-445 second and other intervals (see Figure 3). Given that the velocity of the Taylor bubble/liquid slugs is $0.3 \mathrm{~m} / \mathrm{s}$ this implies Taylor bubble lengths of $13-20 \mathrm{~m}$, larger than the height of the column. This is due to the fact that, when a bubble has burst at the top there are periods when the flow consists of a core open to atmosphere surrounded by a draining 
layer of liquid on the wall. The draining liquid accumulates at the bottom and another liquid slug/Taylor bubble then moves up the column. This behaviour is continues at the higher gas velocities. The mechanism of bubbles bursting at high gas flowrates was studied in detailed by Mohammed et al. (2018). Figure 4 shows a schematic drawing of flow structure at high gas flowrate (churn flow regime). The gas build up and push the liquid to create a very long bubble which appear as an open core after the bubble bursts this is shown in column (B).

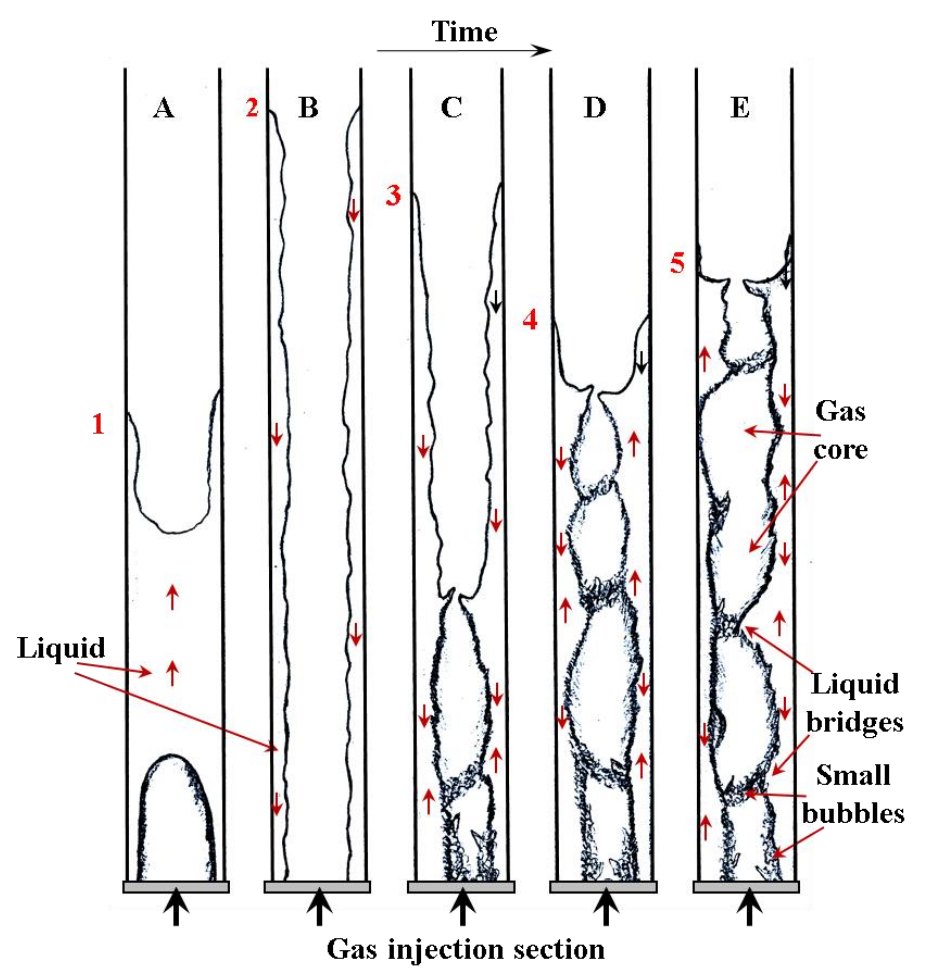

Figure 4: Schematic drawing showing the mechanism of large bubbles bursting in columns of viscous liquids at high gas flowrates. The arrows in the figure correspond to the direction of the liquid flow, the numbers at the top section of the column corresponding to the liquid levels in the column. $D$ and $E$ are the more common structure for this flow regime. A-C occur when the liquid accumulates at the bottom of the column and the gas build up and rise as one long bubble and carry the whole liquid up to drain again as a falling film. The gas superficial velocity is $0.566 \mathrm{~m} / \mathrm{s}$ (Mohammed et al., 2018).

In addition, in the examples at the three higher gas superficial velocities illustrated in Figure 3and Figure 5, another type of behaviour can be seen. This takes the form of a 
higher frequency oscillation where the void fraction fluctuates around a value of 0.2. From studies of other similar two-phase flows, it shows many of the characteristics of churn flow. The PDF of the entire time series is similar to those at lower gas flows. However, if the PDF from the data of these churn flow regions is calculated separately, it does not show the two characteristic peaks but a broad single peak. For a gas superficial velocity of 0.21 $\mathrm{m} / \mathrm{s}$, this is the data from between 100 and 160 seconds (see Figure 3). For $0.223 \mathrm{~m} / \mathrm{s}$, it is from110 to 170 seconds. Also shown on these PDFs (Figure 5) are the data for the succeeding core flows, i.e. for $160-390\left(\right.$ at $\left.u_{g \mathrm{~s}}=0.210 \mathrm{~m} / \mathrm{s}\right)$ and $170-340\left(\right.$ at $\left.u_{g \mathrm{~s}}=0.223 \mathrm{~m} / \mathrm{s}\right)$ seconds (Figure 3) respectively.

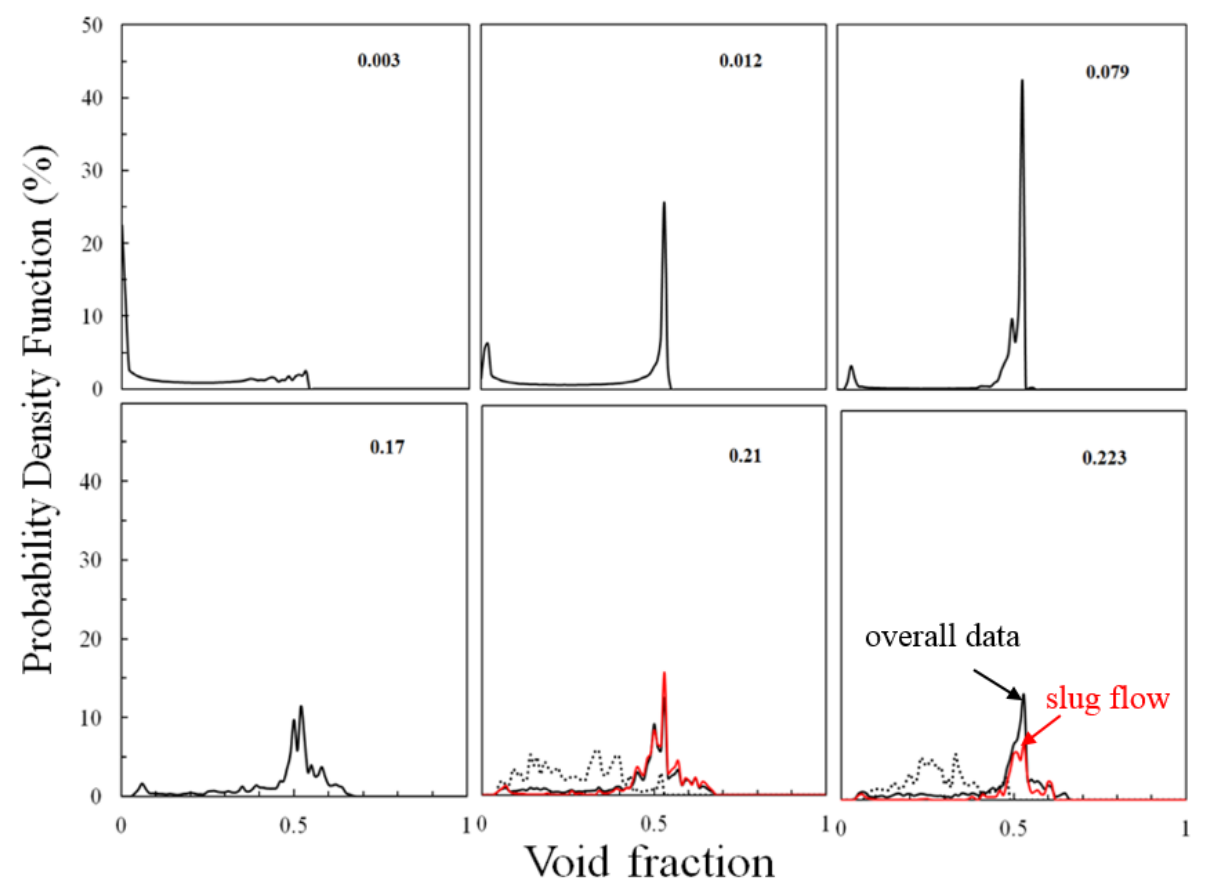

Figure 5: PDFs of void fraction at different gas superficial velocities, values in $\mathrm{m} / \mathrm{s}$ indicated on the individual plots. —_ overall data (black); ..... churn flow; — slug flow (red). The number on the top of each graph indicates superficial gas velocities $(\mathrm{m} / \mathrm{s})$.

As shown by the tomography data, and confirmed by visual observations, for many of the flow conditions employed, the gas (in the form of Taylor bubbles) occupies a substantial part of the column cross section. These bubbles are interspersed with packets of liquid. In these 
very-viscous liquid experiments, the lower end of the Taylor bubbles are rounded. There is neither recirculation at their rear nor gas entrainment creating millimetre-sized bubbles from this region. However, there are small bubbles dispersed in the liquid phase whose sizes are $400 \mu \mathrm{m}-3 \mathrm{~mm}$. Azzopardi et al. (2014) also reported small bubbles in their study of glucose syrup behaviour in the column employed in the present experiments. They reported smaller bubble sizes $(\sim 100 \mu \mathrm{m})$.

At the top free surface of the column, the viscous liquid stretches as the Taylor bubble rises forming a thinning film that bursts when the film drains until it cannot hold the pressure of the bubble. The viscous liquid film folds entrapping gas forming bubbles as reported by Pandit et al. (1987), (1987), Philip et al. (1990) and Bird et al. (2010). Continuous stretching and folding due to the train of Taylor bubbles create tiny bubbles. A bubbly liquid forms the top of the liquid column, and progressively extend downward by flow-induced gas stirring. As a result, silicone oil becomes milky in appearance. The mechanism of the Taylor bubble bursting and rupturing/retracting of the liquid is shown in Figure 6. 


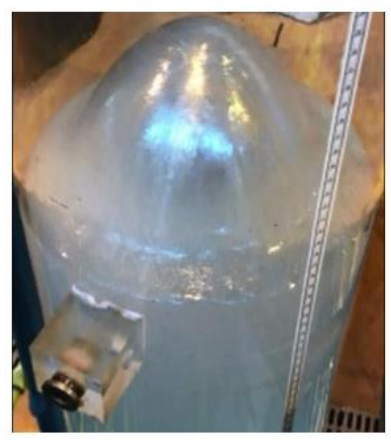

(a)

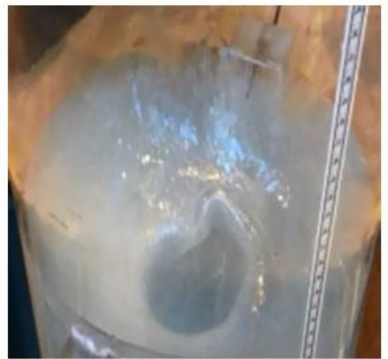

(d)

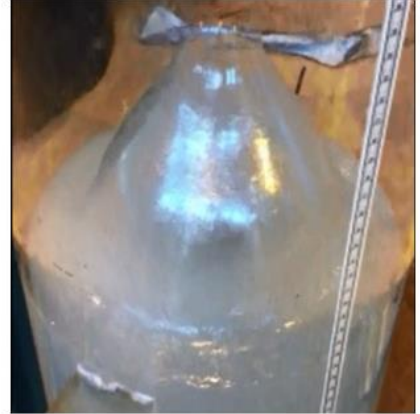

(b)

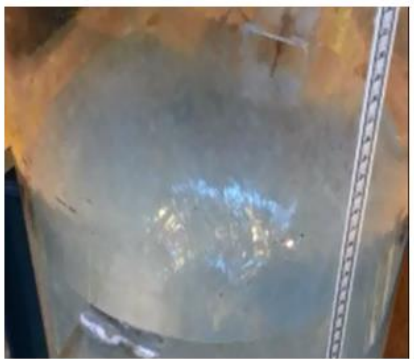

(e)

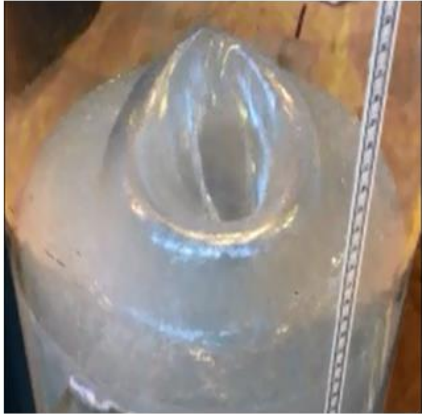

(c)

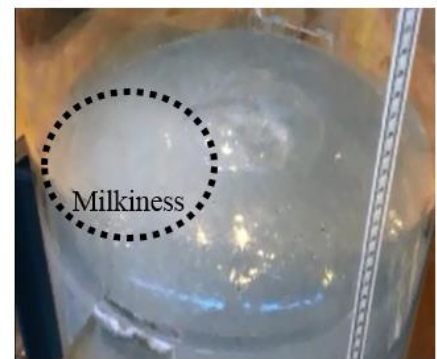

(f)

Figure 6: Mechanism of the Taylor bubble bursting and rupturing/retracting of the liquid at the top surface; (a) bubble is just covered by a thin film of liquid (Taylor bubble just to burst), (b) bursting of a Taylor bubble, (c) falling down of the liquid film entrapping gas bubbles, (d) retracting of the liquid, (e) next Taylor bubble to arrive, (f) liquid level is rising up again (milkiness is obvious).

It was also observed that, as the gas flow rate increases the probability of coalescence between successive Taylor bubbles increases. The gas Reynolds number of the flow $\left(R e_{\text {slug }}=\right.$ $\frac{\rho_{l} \cdot u_{g} \cdot D}{\mu_{l}}$ ) ranged from $10^{-2}$ to $10^{1}$ in the experiments, suggesting that the flow is laminar in all the cases. In addition, the buoyancy Reynolds number (see equation 4.2) suggests that the Reynolds number of the flow is of the order 1. The flow around the Taylor bubble is more streamlined leading to the formation of elliptical rear end.

\subsection{Average properties of the flow}

Figure 7 shows the variation of time-averaged void fraction obtained from the two ECT planes.

The trend shows a good agreement between the two planes. The void fraction increases with 
increasing gas flow as expected. In addition, mean void fraction can be estimated by monitoring the top surface of the column using the following equation; $\left(L_{x}-L_{0}\right) / L_{x}$, where $L_{0}$ is the original reference (static) height of the liquid $(3.27 \mathrm{~m})$ and $L_{x}$ is the mean height of the top surface of the aerated liquid. There is good agreement between the two methods at low-to-moderate gas superficial velocities. At higher gas flows, it is more difficult to determine the position of the top surface because of the oscillations which occur. In addition, sheared bubbles which remained on the wall, which drained away slowly, and the liquid milkiness effects make recording of the mean top surface height, $L_{x}$ difficult. A further set of values of void fraction can be obtained from the pressure measurements. For the lower gas flow rates, where the flow is bubbly, the pressure difference between the two lowest stations is essentially the gravitational head. Void fraction can be calculated from the difference in mean pressures by:

$$
\varepsilon_{g}=1-\frac{p_{1}-p_{2}}{\rho_{L} g\left(H_{2}-H_{1}\right)}
$$

A good agreement can be seen in Figure 7 with the values obtained from ECT and level swell at gas velocities in the range 0.0008 to $0.0155 \mathrm{~m} / \mathrm{s}$, i.e., in bubbly flow. Values of void fraction have also been calculated using (3.1) for the runs with higher gas velocity, i.e., in slug and churn flow (Figure 7). For higher gas flowrates, the values predicted using pressure (open diamonds) deviates widely. However, this is not unexpected and will be discussed further below. It should be noted that, the points marked as slug and churn flow in Figure 7are specific to the regions identified in last three graphs presented in Figure 3(where the slug and churn features are extracted simultaneously for each graph or flow condition). 


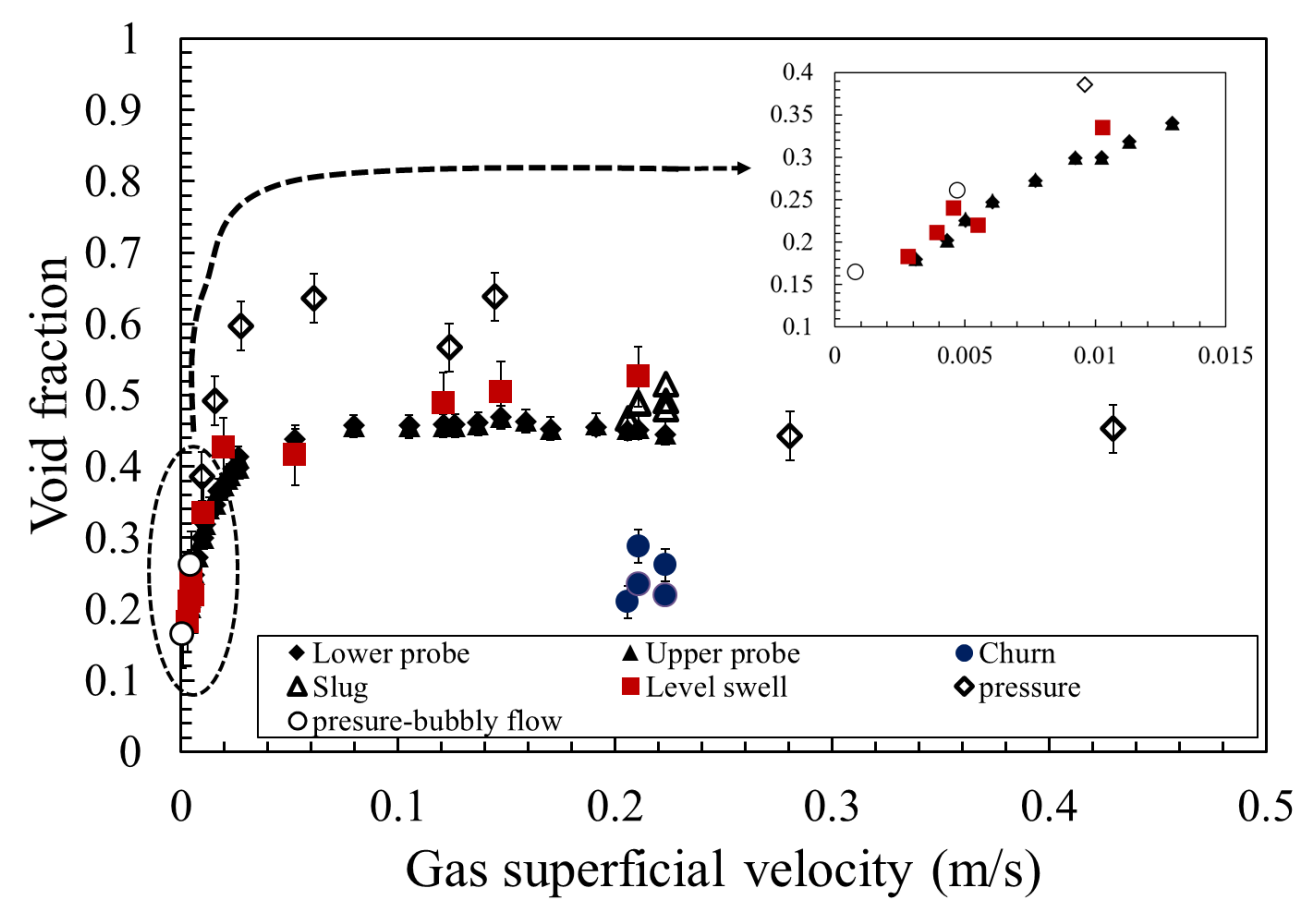

Figure 7: Variation of the void fraction obtained from the two ECT planes, level swell and pressure measurements. Vertical bars correspond to the standard error of the void fraction data measured from the ECT.

The pressure gradient (pressure difference divided by distance between tappings) has been obtained for tappings 1 and 2. It was not possible to obtain that for tappings 2 and 3 as the top tapping was not always below the top surface of the aerated liquid column. The results are illustrated in Figure 8, as pressure gradient non-dimensionalised by the liquid only pressure gradient, and show that the values initially fall in the bubbly and slug flow patterns. For bubbly flow, the pressure gradient is essentially the two-phase head which, because the void fraction is increasing with increasing gas superficial velocity, will decrease. In slug flow this approach is not be valid. Here, the pressure drop is essentially the head across the liquid slug portions of the flow and the frictional pressure drops for the liquids slugs. As the liquid portion of the unit slug (a Taylor bubble and a liquid slug) decreases with increasing gas superficial velocity, the pressure gradient is expected to decrease. Pioli et al. (2012) applied a slug flow model to 
a liquid of viscosity similar to that in the present work and obtained good agreement with their experiments.

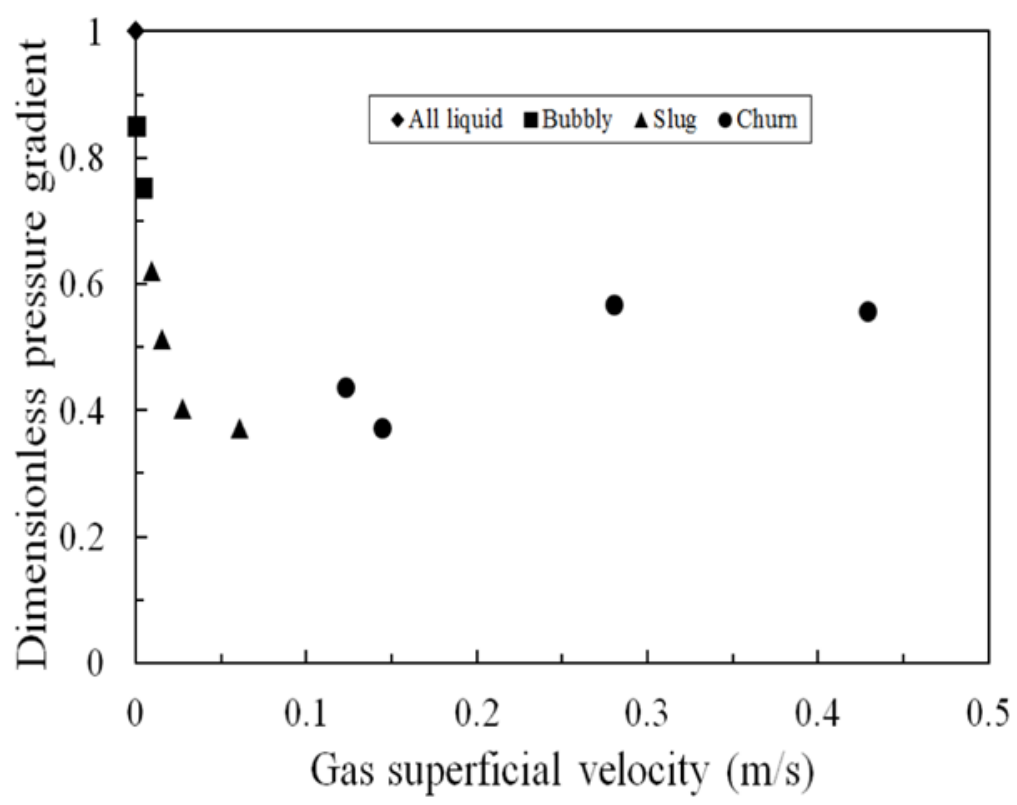

Figure 8: Mean pressure gradient between tappings 1 and 2 made dimensionless by considering the pressure gradient for liquid only

A powerful way to calculate void fraction is the Drift Flux approach proposed by Zuber and Findlay (1965) who identified that the gas velocity (gas superficial velocity divided by void fraction) was proportional to the flow rate (gas superficial velocity):

$\frac{u_{g s}}{\varepsilon_{g}}=C_{0} u_{m i x}+u_{d}$

where $C_{0}$ is the constant called distribution coefficient, $u_{\text {mix }}$ is the mixture velocity and $u_{d}$ is a drift velocity, in slug flow (in a bubble column), this might be equated to the rise velocity of a single Taylor bubble. Zuber and Findlay noted that if the range of flow rates covered by a data set extended over more than two flow patterns, there could be two versions of (3.2), with different constants for bubble/slug and churn/annular flow. The two line fit has been recently reported by Sharaf et al. (2016). Re-examination of the fluidized bed data of Makkawi and Wright (2002), Saayman et al. (2013) and Qiu et al. (2014), shows that their data also exhibits 
this two straight line characteristic. The data from the present experiments has plotted in this way and is shown in Figure 9. It is seen that there are indeed two lines of slightly different slopes. For lower gas flow rates, $C_{0}=2.03$ and $u_{d}=0.0123 \mathrm{~m} / \mathrm{s}$ whilst for higher gas flow rates the corresponding values are 2.23 and $-0.0172 \mathrm{~m} / \mathrm{s}$. The regression coefficients, indicating the goodness of fit to the straight lines are 0.9996 and 0.9981 respectively. It might be considered that the transition between the two regions could be determined from the intersection of the two straight lines. From the values of $C_{0}$ and $u_{d}$ above; the transition gas superficial velocity is $0.11 \mathrm{~m} / \mathrm{s}$.

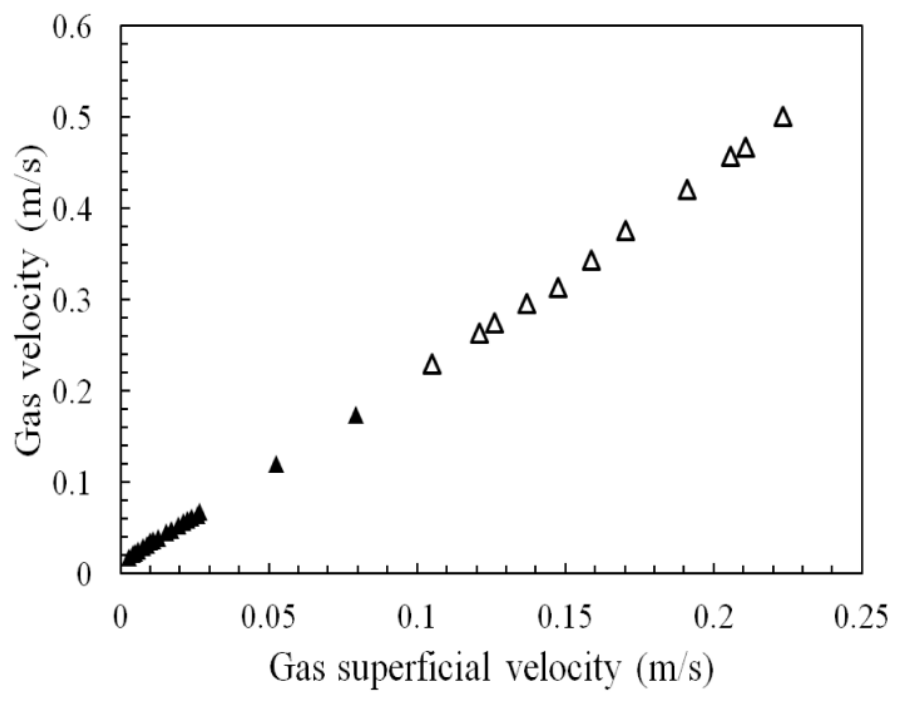

Figure 9: Drift flux plot for present data. Closed symbols - lower gas flow rates; open symbols - higher gas flow rates.

3.3 Dynamic properties of the flow: Pressure variations and velocity of inner structures

Pressure oscillations within the column increase in amplitude with increasing gas superficial velocity. Time traces of pressure show specific patterns which can be associated to each flow regime. 
Examples of the output from the pressure transducers, converted from voltages to pressure, are shown in Figure 10.

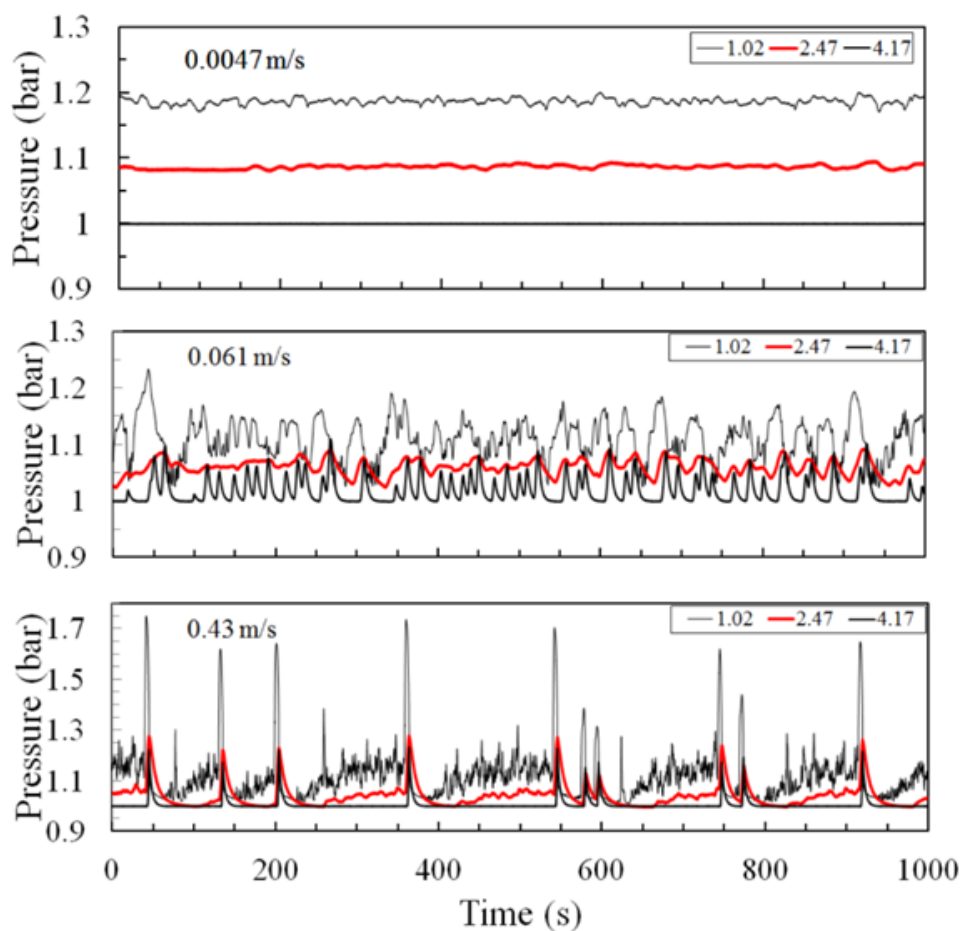

Figure 10: Time series of wall pressure at different axial positions $(1.02 \mathrm{~m}, 2.47 \mathrm{~m}$ and $4.17 \mathrm{~m}$, respectively, from the gas inlet at the bottom of the column). Gas velocities: (a) $0.0049 \mathrm{~m} / \mathrm{s}-$ bubbly flow; (b) $0.061 \mathrm{~m} / \mathrm{s}$ - slug flow; (c) $0.43 \mathrm{~m} / \mathrm{s}$ transition to churn flow.

The observations from Figure 10 can be summarised as below.

1. At the low gas superficial velocity of $0.0047 \mathrm{~m} / \mathrm{s}$, the trends show almost constant pressure drop from the low to middle stations. However, for velocities of 0.0008 to $0.0096 \mathrm{~m} / \mathrm{s}$, the pressure at the upper station is atmospheric indicating that the aerated liquid level has not reached this point. Reference to the void fraction traces at the velocity within this range 
in Figure 3, as well as observations through the transparent wall of the column, indicates that the flow consists of bubbles which are smaller than the pipe diameter.

2. Very clear oscillations in the pressure traces from all three transducers can be seen in the example from the next gas velocity. From Figure 3, and direct observation, this is identified as slug flow where the bubbles occupy a significant part of the pipe cross-section and are of cylindrical shape with hemispherical ends. This occurs over gas superficial velocities of 0.0155 to $\sim 0.1 \mathrm{~m} / \mathrm{s}$.

3. At the highest gas velocity shown in Figure 10 there are synchronous oscillations at the three measuring points, suggesting that the structure in the flow are as long as the pipe and that liquid level occasionally rise beyond the upper station. The lower station show more complex patterns which could be associated with entrance phenomena (i.e formation of gas bubbles at the nozzles).

Taylor bubble velocities were obtained from the cross correlation of the time series of void fraction from the two planes of the ECT. This gives a delay time which can be combined with the spacing between the two planes to give a mean velocity of the structures in the flow. A cross-correlation can be expressed mathematically as; $R_{x y}(\tau)=\lim _{T \rightarrow \infty} \frac{1}{T} \int_{0}^{T} x(t-\tau) y(t) d t$. (where $R_{x y}(\tau)$ is the cross-correlation function, $x(t)$ and $y(t)$ are the mean void fraction data from upstream sensor and downstream sensor of the ECT respectively and $\mathrm{T}$ is the total time of the acquired data. If the structures of the flow are coherent over the length of the sensor, then there will be a strong discernible peak in the resulting correlogram. The time delay $\left(\tau_{\max }\right)$ corresponding to this peak (i.e. when the cross-correlation function, $R_{x y}(\tau)$ is maximum) represents the transit time of the flow structures between upstream sensor of the ECT and the downstream sensor. The structure velocity (which is defined as $L / \tau_{\max }$, where $\mathrm{L}$ is the distance between two ECT planes) can be then easily obtained. 
Figure 11a shows the variation of the structure velocities with gas superficial velocity. The trend shows a linear relationship over the gas flow rates covering slug flow. Similarly, the velocities of the dominant structures of other flow patterns can similarly be obtained from delay times extracted from the cross-correlation of the times series from the two ECT planes which is combined with the inter plane spacing. The dominant frequencies of the oscillations in void fraction have been extracted using power spectrum analysis as described by Kaji et al. (2009). Here, Power Spectrum Densities (PSDs) have been obtained by using the Fourier transform of the auto-covariance functions. Because the auto-covariance function has no phase lag, a discrete cosine transform can be applied. The trends of the dominant frequencies with gas superficial velocity are presented in Error! Reference source not found.b. Also plotted are the frequencies obtained by counting the number of Taylor bubbles per unit time from both the time series of void fraction and those for wall pressure. There is good agreement between all three except at the highest gas velocities. In addition, the frequency for those portions showing churn flow characteristics has been extracted using a modification of the approach suggested by Luo et al. (2004). The PSD was obtained from which the average frequency, $f_{n}$, was determined from:

$f_{n}=\sum_{j=0}^{N-1} f_{j} E_{j}$

where $E_{j}=\frac{G\left(f_{j}\right)}{\sum_{j=0}^{N-1} G\left(f_{j}\right)}$ with $G\left(f_{j}\right)$ is the PSD

Figure $11 \mathrm{~b}$ shows that for gas superficial velocity less than $0.02 \mathrm{~m} / \mathrm{s}$, frequencies increase with increasing gas superficial velocity. Beyond this gas velocity, frequency is unchanging until the transition point identified from Figure 9 occurred. Beyond this point, the frequency of Taylor bubbles/slugs decreases with increasing gas flow rate. Beyond the transition to churn flow, the slug flow frequency remains constant, at minimum value. The corresponding frequencies for the churn region were much higher (nearly two orders of magnitude) but also appear independent of gas superficial velocity. The first change in trend 
might be linked to the bubbles not filling the greater part of the cross-section of the column at these low velocities.
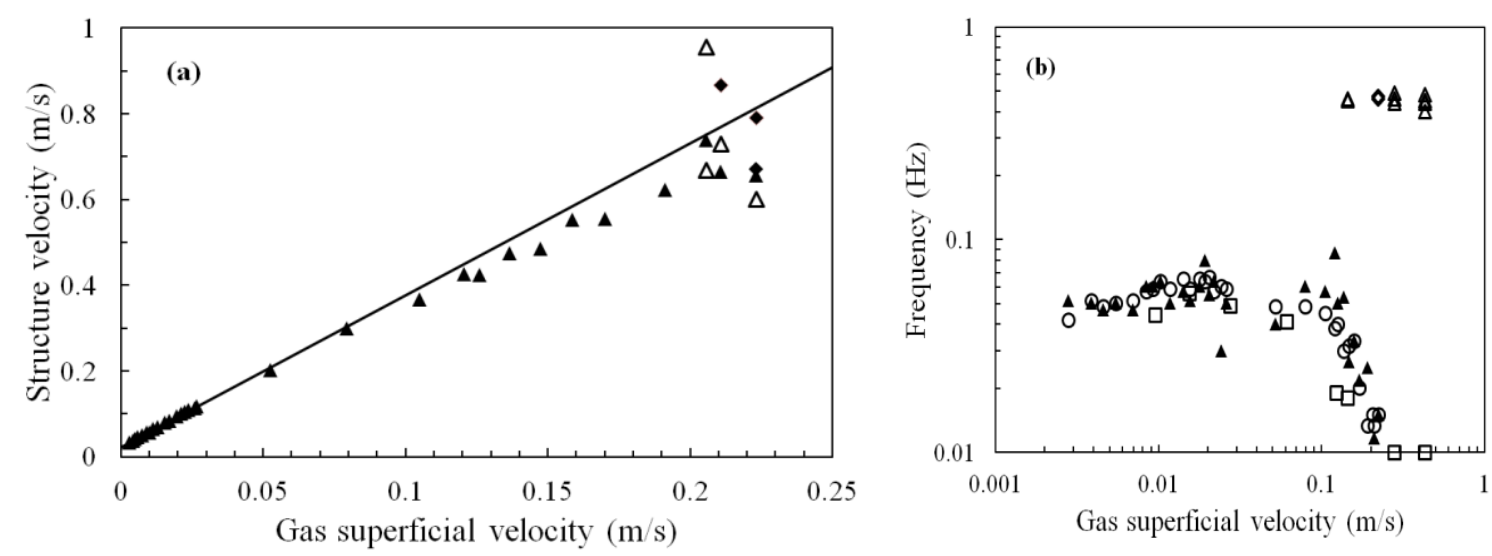

Figure 11: (a) Variation of the structure velocity with gas superficial velocity; experimental data, line is (3.2) with $\mathrm{CO}=3.55$ and $u d=0.022 \mathrm{~m} / \mathrm{s} ; \square$ velocity from slug regions of the flow; • velocity from churn region of the flow. (b) Variation of frequency of periodic structures with gas superficial velocity; $\Delta$ Overall from ECT/PSD; $\circ$ Slugs from counting - ECT; $\square$ Slugs from counting - wall pressure; $\Delta$ Churn from PSD -wall pressure; $\diamond$ Churn from PSD - ECT

\subsection{Regime transitions}

Experimental results confirm that transitions are not deterministic but probabilistic.

It is instructive to investigate this further. This duality can be best seen in the time trace of void fraction shown in Figure 3 for the highest gas superficial velocity presented there, $0.223 \mathrm{~m} / \mathrm{s}$. At this higher gas superficial velocity, the time traces (Figure 3) showed clear slug flow during the times 0-110, 164-343 and 400-600 seconds. There is different type of flow at the other times. it shows fluctuations more akin to churn flow. This is supported by the PDFs shown in Figure 5. For slug flow period, the PDF in Figure 5 shows the characteristic two peak signature of slug flow. However, the peak at low void fraction is not strong. The 110-160 second PDF (i.e. dotted trend in Figure 5, at $U_{g s}=0.223 \mathrm{~m} / \mathrm{s}$ ) has the single broad peak characteristic of churn flow. From the time series (Figure 3), it can be estimated that the flow is $22 \%$ of the time in churn flow at 
this highest gas superficial velocity $(0.223 \mathrm{~m} / \mathrm{s})$. Similar information can be extracted from the wall pressure time series such as those presented in Figure 10. The variation of this parameter with gas superficial velocity can be seen in Figure 12 and illustrates the decrease of relative slugging time with increasing gas superficial velocity. Another notable feature of the time series plots is the rising void fraction seen just before the arrival of the next liquid slug. This indicates thinning of the film of liquid on the walls. It occurs, most likely but not exclusively, for longer intervals between slugs.

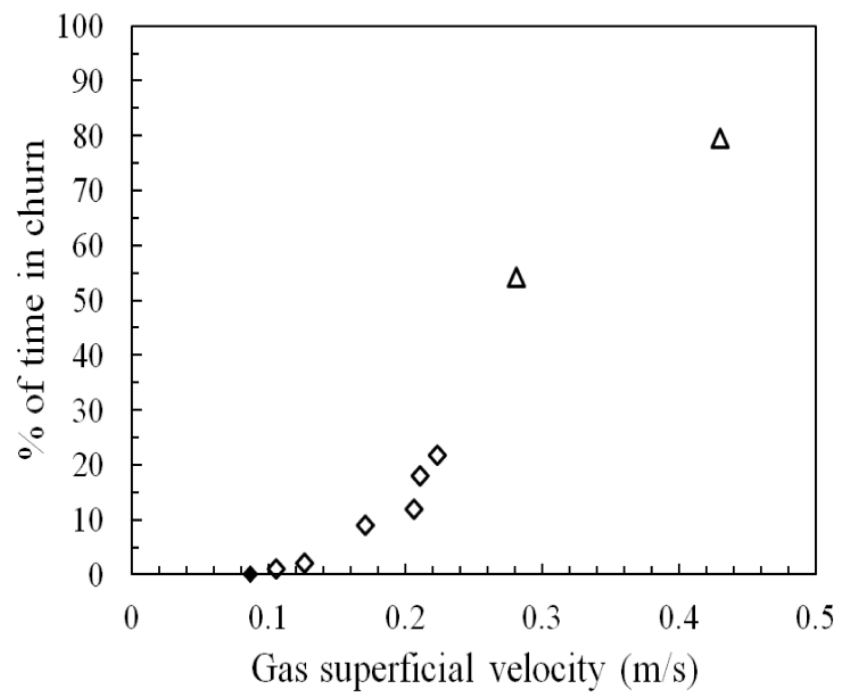

Figure 12: Fraction of time the flow is in churn flow. The closed symbol indicates the transition between the two lines in the drift flux plot.

\section{Discussion}

\subsection{Bubbly flow}

The stability of the bubbly flow pattern is limited to very low gas superficial velocities and low average void fractions (about 20 vol. \%) when compared with gas-low viscosity liquid flows. Even at the lowest gas velocities studied, the bubbles formed by the gas emerging from 
individual nozzle very quickly coalesce to create a stream of spherical bubbles. They differ considerably from the many small, ellipsoidal bubbles and slightly larger spherical cap bubbles which occur with low viscosity liquids. These bubbles are of diameters $140-180 \mathrm{~mm}$, i.e., not yet large enough to fill the entire pipe. Similar large bubbles have been reported in fluidized beds. The reason for this peculiar characteristic is due to the high viscosity of the liquid, (and the very low Reynolds numbers of the flow) which is suppressing bubble breakup due to turbulence. This means that the bubbles grow by coalescence, whose efficiency is controlled by void fraction. The viscous dominated version of the equation of Gaddis and Vogelpohl (1986) has been used to determine the size of bubbles formed at the nozzles. These were compared with the sizes measured in the flow. This gave bubble sizes from 35 to $72 \mathrm{~mm}$ for gas superficial velocities of 0.0008 to $0.0155 \mathrm{~m} / \mathrm{s}$ and ratios of bubble size to inter-nozzle spacing of 0.48 to 0.96 . These are 2-3 times smaller than those extracted from the ECT output, e.g., 135 to $185 \mathrm{~mm}$ at a gas superficial velocity of $0.003 \mathrm{~m} / \mathrm{s}$, confirming the efficiency of coalescence processes.

The bubble velocity is calculated by modifying the original approach by Allahwala and Potter (1979). The modification proposed here used a Froude number more relevant to the present conditions than the original value of 0.35 suggested by these authors. It also uses a value of $C_{0}$ of 3.55 found for the slug flow data instead of the original value of 1.0. The equation has the form:

$\frac{U_{b}}{\sqrt{g D}}=\operatorname{Fr}\left[\tanh \left(3.6 \varepsilon_{g p}^{0.45}\right)\right]^{0.55}+\frac{C_{0} u_{g s}}{\sqrt{g D}}$

The data extracted from the present experiment at the lowest gas velocity studied are scattered around the line for equation (4.1) as shown in Figure 13. 


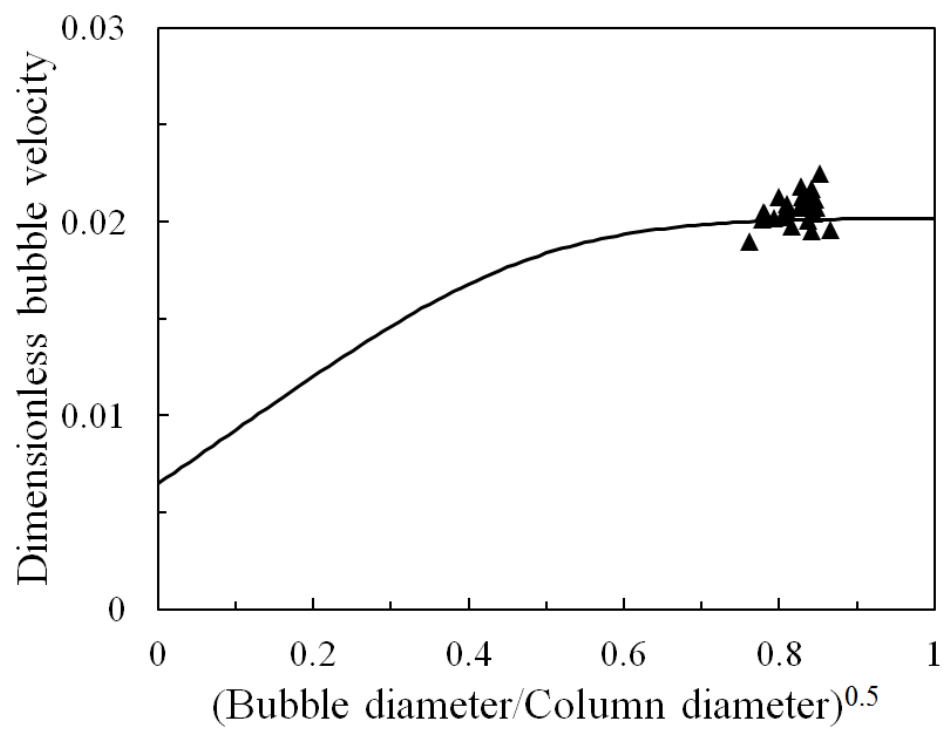

Figure 13: Comparison of measured bubble velocity, as Froude number $=\mathrm{Ub} / \square(\mathrm{gD}) \boldsymbol{\Delta}$, with equation (4.1) modified from Allahwala and Potter (1979) —.

\subsection{Slug Flow}

For low viscosity, the model of slug flow consists of large bubbles interspersed between liquid slugs. There is a transfer of gas from the larger bubbles (formed just above the gas inlet) to small bubbles dispersed in the liquid slug. The quantity of these small bubbles decreases with decreasing pipe diameter and increasing liquid viscosity (Philip et al., 1990, Kuncová and Zahradník, 1995). Pure slug flow was stable until gas superficial velocity of $0.11 \mathrm{~m} / \mathrm{s}$.

The rise velocity of the large bubbles was first studied analytically by Dumitrescu (1943) and experimentally by Davies and Taylor (1950) for flow in stagnant liquids. They expressed the rise velocity, $U_{b}$ as; $U_{b}=F r_{1} \sqrt{g D}$ (where $F r_{1}$ is the Froude number, $D$ is the pipe diameter and $g$ is the acceleration of gravity). They proposed values for Froude number of 0.351 and 0.328 respectively.

Viana et al. (2003) studied the effects of liquid viscosity, surface tension and pipe diameter on the bubble velocity. They proposed a new expression for the Froude number, Fr, 
based on Eötvös number, Eo, and a dimensionless inverse viscosity, also known as the buoyancy Reynolds number, $\operatorname{Re}_{b}$. These are defined as:

Eo $=\frac{g \rho_{l} D^{2}}{\sigma} \quad$ and $\quad R e_{b}=\frac{\sqrt{D^{3} g\left(\rho_{l}-\rho_{g}\right) \rho_{l}}}{\mu_{l}}$

Where $\rho_{l}$ is the liquid density, $\rho_{g}$ is the gas density, $\mu_{l}$ is the liquid dynamic viscosity and $\sigma$ is the surface tension.

Viana et al. (2003) developed an expression for the Froude number $\mathrm{Fr}_{2}$ as a function of Eötvös number, Eo. For small buoyancy Reynolds $\left(\operatorname{Re}_{b}<10\right), \mathrm{Fr}_{2}$ is given by

$$
\mathrm{Fr}_{2}=\frac{0.009494}{\left(1+\frac{6197}{\mathrm{Eo}^{2.561}}\right)^{0.5793}} \operatorname{Re}_{b}^{1.026}
$$

The above work was conducted for isolated bubbles rising in stagnant liquids. In the case where there is finite gas and liquid flow rates, the work of Nicklin (1962) proposed a robust and predictive equation to predict $U_{b}$ :

$U_{b}=C_{0}\left(u_{g s}+u_{l s}\right)+\operatorname{Fr} \sqrt{g D}$

where $u_{g s}$ is the gas superficial velocity, i.e., volumetric flow rate per column cross-sectional area, and $u_{l s}$ is the corresponding parameter for liquid. Obviously, in the present work $u_{l s}=0$. Nicklin (1962) used $C_{0}=1.2$ but noted that higher values were more appropriate as the flow rates diminished. The coefficient $C_{0}$ was studied by Collins et al. (1978), Fabre and Liné (1992), Dukler and Fabre (1994) and Guet et al. (2004), the last of who suggested that $C_{0} \rightarrow 5$ for very high viscosity liquids, (Collins et al., 1978) obtained a value of 2.27 from their modelling work and Fabre and Liné (1992) who suggest 2.29. Because of the uncertainty in the value of $\mathrm{C}_{0}$ noted above, a different approach was taken here. A linear fit was made to those data points at lower gas velocities which showed this characteristic. This gave values of $C_{0}=$ 
3.45 and $u_{d}=0.022 \mathrm{~m} / \mathrm{s}$. The former is in between the values of 2.27 and 5 cited above whilst the latter is close to the value $0.015 \mathrm{~m} / \mathrm{s}$ from equation (4.3).

As shown in Figure 5, the first peak of the Probability Density Function of void fraction corresponds to the void fraction, $\varepsilon_{g s}$ in the liquid slug while the second peak is related to the void fraction of the Taylor bubble. These two peaks can be used to extract quantitative information about the lengths of the Taylor bubbles and slugs. Khatib and Richardson (1984), proposed an equation from which the average lengths of the Taylor bubbles and slugs, using information from the PDF, can be predicted. That is:

$\frac{L_{S}}{L_{u}}=\frac{\varepsilon_{g}-\varepsilon_{g T B}}{\varepsilon_{g s}-\varepsilon_{g T B}}$

where $L_{s}$ is the slug length, $L_{u}$ is the unit slug length $\left(L_{u}=L_{s}+L_{T B}\right.$, where $L_{T B}$ is the length of the Taylor bubble), $\varepsilon_{g T B}$ and $\varepsilon_{g s}$ are the void fractions in the Taylor bubble and liquid slug parts respectively and $\varepsilon_{g}$ is the mean void fraction (extracted from the time series obtained by an Electrical Capacitance Tomography (ECT) sensor). $L_{u}$ can be obtained from the structure velocity $u_{s t}$ and the frequency of the Taylor bubble, $f\left(\right.$ i.e. $\left.L_{u}=u_{s t} t f\right)$.

Mean lengths of Taylor bubbles and liquid slugs have be extracted using the method of Khatib and Richardson (1984) using (4.5). These mean lengths are plotted in Figure 14, taking into consideration only those data which were fully in slug flow, i.e., those being below the transition gas velocity $(0.11 \mathrm{~m} / \mathrm{s})$ identified in Figure 9. 


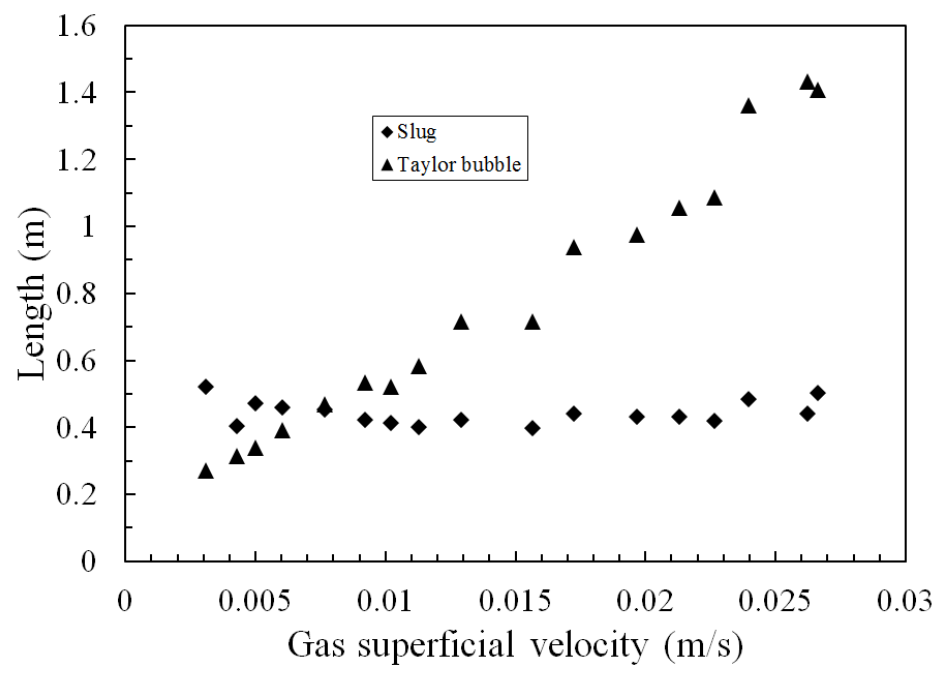

Figure 14: Mean lengths of Taylor bubbles and liquid slugs in the slug flow region.

During slug flow, the film thickness around a Taylor bubble will be constant except for a region around the nose and tail of the bubble. This is because there is a constant flow of liquid downwards. Azzopardi et al. (2014) noted that the rate of flow is related to the liquid displaced by the Taylor bubble. However, it is only in those experiments, such as Clanet et al. (2004) and Llewellin et al. (2012), which have a closed top, that all of liquid displaced by the Taylor bubble flows downwards. For those cases, where the top of the column is open to atmosphere, the top surface of the liquid is pushed up and so only part of the displaced liquid flows down. When the nose of the Taylor bubble reaches the top of the aerated column and bursts, the feed of liquid to flow downwards ceases and the film thins and drains down to the next liquid slug as considered by Rana et al. (2015). In the present experiments and those of Azzopardi et al. (2014), the length of the Taylor bubble can be at least at tall as the aerated column, i.e., there is complete gas core. For those cases, the drainage of the film becomes particularly important as sufficient drainage of liquid is required for an accumulation at the bottom for the next liquid slug, and hence Taylor bubble, to form.

\subsection{Transition to churn flow}


As noted above, the sequences in Figure 3 of churning flow and of increase in void fraction with time merit closer investigation. An example from the run at a gas superficial velocity of $0.223 \mathrm{~m} / \mathrm{s}$ is shown in Figure 15 as plots of the time series of film thicknesses from the two ECT measurement planes respectively. Film thickness, $\delta$, is obtained from void fraction using the geometric relationship, $\delta=(D / 2)\left(1-\sqrt{ } \varepsilon_{g}\right)$. In Figure 15, portions of the flow with film thickness decreasing with time and obvious waves on the surface can be identified. If the waves at 187 and 211 seconds are considered, the thickness from the upper probe arrives before that from the lower probe indicating that the waves are travelling downwards. From the time delay between the two signals the wave velocities is determined as -0.061 and $-0.049 \mathrm{~m} / \mathrm{s}$ respectively. Benjamin (1957) determined the velocities of infinitesimally small waves from linear stability analysis. For film Reynolds number $\rightarrow 0$, his analysis gave a wave velocity as being equal to $-3\left\langle u_{f}\right\rangle$. For the present physical properties and film thickness this yields a value of $-0.034 \mathrm{~m} / \mathrm{s}$, i.e., lower than the values detailed above. However, the waves are of much greater amplitude than what is considered in linear stability analysis. Reports in the literature of larger-amplitude, non-linear waves show that they velocities higher than $-3\left\langle u_{f}\right\rangle$. For example, Meza and Balakotaiah (2008) have studied such waves over a range of physical properties and though they did not study viscosities as high as in the present work, their results point to higher wave velocities which would give better agreement with the experimental results above. 

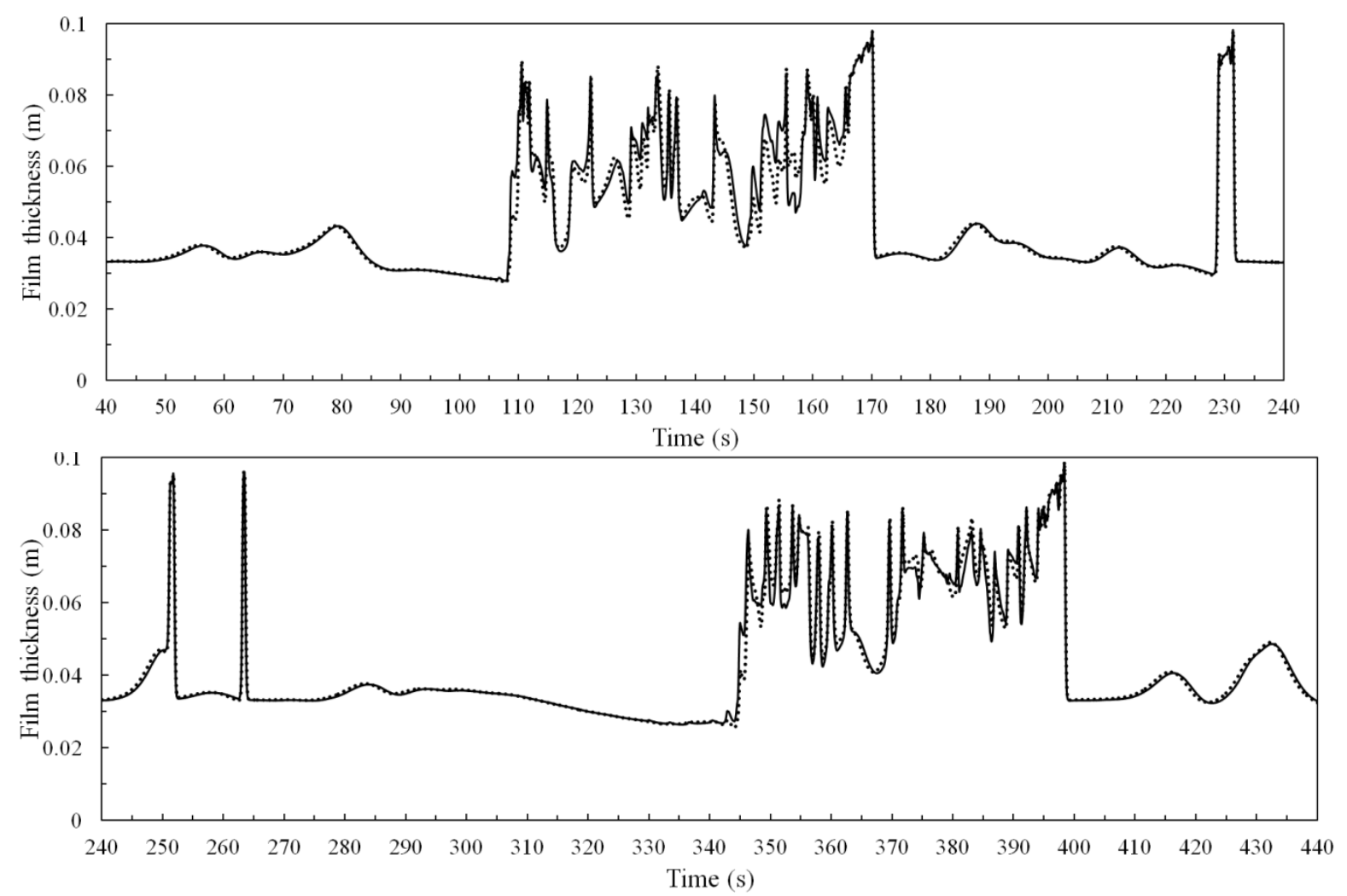

Figure 15: Time series of film thickness from both ECT measurement planes showing waves on film around Taylor bubbles, churn regions and liquid slugs. — Lower plane; •...• upper plane. Gas superficial velocity $=0.223 \mathrm{~m} / \mathrm{s}$

The velocities of these waves can be contrasted with the liquid slugs seen at $\sim 170$ (back) and $\sim 230$ (front) seconds where the increase in film thickness from the lower probe occurs before that from the upper probe indicating upward flow. The velocity of the slugs extracted from the time delay are +0.75 and $+0.49 \mathrm{~m} / \mathrm{s}$ respectively. Churn flow can be seen between 110-170 and 340-390 seconds. Here the films are thicker than in in the Taylor bubble region. The fronts and backs of the waves can be travelling in different directions. It is a very confused picture justifying the description of churning and hence the name: churn flow.

Figure 16 reproduces a void fraction time series from the glucose syrup experiments of Azzopardi et al. (2014). These particular data were obtained at a gas superficial velocity of $0.675 \mathrm{~m} / \mathrm{s}$. The parts which are in churn flow and the increase in void fraction are marked. The axial length of the electrodes in that work was $0.125 \mathrm{~m}$ compared to $0.036 \mathrm{~m}$ in the present 
experiments. Not surprisingly, the features in Figure 16are less well resolved that those in Figure 15.

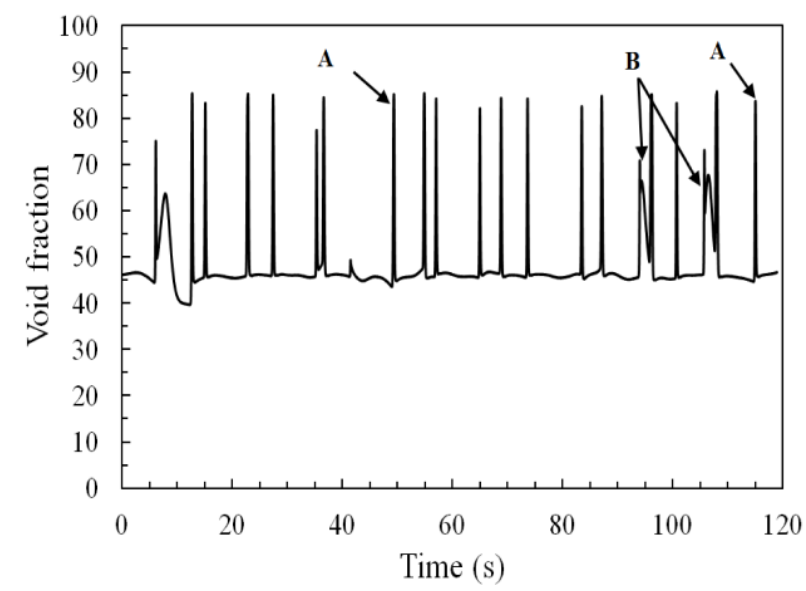

Figure 16: . Film thickness time series for glucose syrup in a $240 \mathrm{~mm}$ diameter column. Gas superficial velocity $=0.675 \mathrm{~m} / \mathrm{s}$. Positions marked A show rising void fraction resulting from a draining film. Positions marked B show areas of churn flow. Data from Azz

For the draining of the liquid film following the rupture of the top "skin" identified, the important forces to be: inertial, gravitational, viscous and surface tension. They employed scaling of the terms of the Navier-Stokes equations for the draining film to obtain expressions for all these forces. Using a balance of forces with appropriate signs according to the directions in which they were acting, they proposed an expression for the draining time. For the present work, the surface tension force can be considered negligible. A simplified version of their expression can be obtained, $\mu_{l} L / \rho_{l} g d^{2}$. Here, $L$ is the height of column over which the film is draining. Inserting appropriate value of these variables yields a drainage time of $\sim 100$ seconds for the present experiments. For the experiments of Azzopardi et al. (2014) which employed glucose syrup the corresponding time was $\sim 20$ seconds. It is noted that for the experiments of 
Rana et al. (2015) this simplified expression suggested a time of 0.25 seconds. Their experimental times were an order of magnitude greater.

Drainage of liquid films on vertical surfaces has been studied in the context of empting of tanks by, e.g., Van Rossum (1958) and OLOUGHLIN (1965). However, what they were analysing differs significantly from the present problem. Therefore, it is important to start from the unsteady balance over an annular ring of film. This results, after some simplification, to:

$\frac{\partial \delta}{\partial t}+\left\langle u_{f}\right\rangle \frac{\partial \delta}{\partial x}=0$

where $\left\langle u_{f}\right\rangle$ is the mean film velocity. This can be solved with the boundary condition $\delta=\delta_{o}$ for all $x$ at $t=0$. Now if the film flow is laminar and its thickness is very small compared to the pipe diameter, the mean film velocity can be determined from the analysis of Nusselt (1916) to be:

$\left\langle u_{f}\right\rangle=\frac{\rho_{l} g \delta^{2}}{3 \mu_{l}}$

Using (4.7), (4.6) can be solved by the method of characteristics to yield:

$\delta=\sqrt{\frac{x \delta_{o}^{2}}{\left(A \delta_{o}^{2} t+x\right)}}$

where $\mathrm{A}=\rho_{L} g / \mu_{L}$

Figure 17 shows a comparison of the thinning of the film as predicted by (4.8). Also shown is the thickness extracted from the ECT data. The initial time was obtained from an estimate of when the slug seen at 170 seconds reached the top of the aerated column. The initial film thickness was calculated from the measured void fraction. The agreement is reasonably good bearing in mind that waves were not considered in the analysis. 
Examination of the thickness of the film relative to the pipe diameter involved in the present work shows it to be $\sim 15-20 \%$.

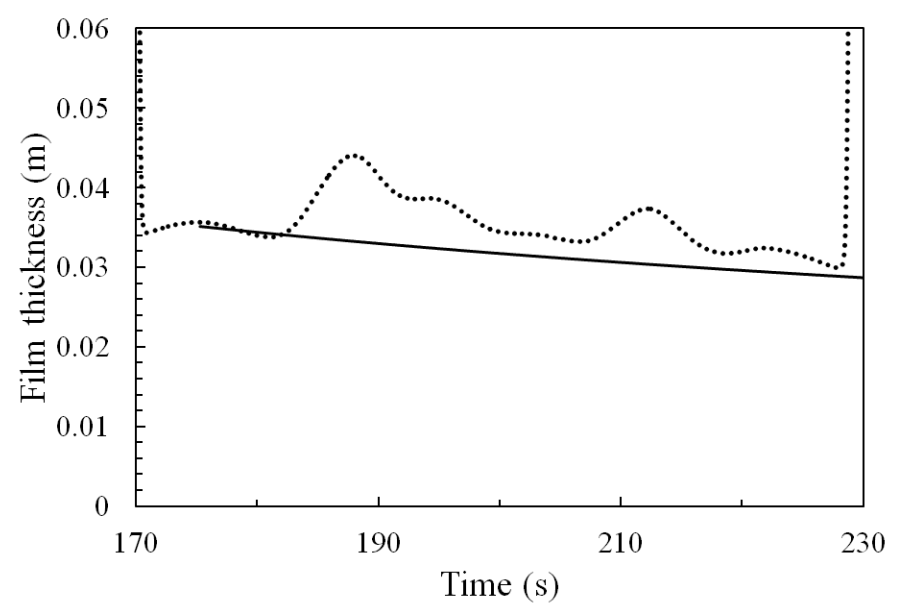

Figure 17: Comparison of film thickness from ECT measurements $(\cdots)$ and predictions of drainage modelling (-). Gas superficial velocity $=0.223 \mathrm{~m} / \mathrm{s}$.

This drainage analysis can be used to obtain the time when the next slug will arrive. The film thickness at the bottom of the column can be used to calculate the volumetric flow rate of liquid either from $\pi D \delta<u_{f}>$ where $u_{f}$ is given by (4.7). The relationship between the height of the pool at the bottom of the column, as a function of the cumulated time, T. is then given by (4.9)

$$
\Delta H=\frac{4}{\pi D^{2}} \int_{0}^{T} Q d t
$$

The results are shown in Figure 18for both the present experiments and those, using glucose syrup, of Azzopardi et al. (2014). Though the gas velocities differ between the two cases, it is noted the initial film thicknesses only show a weak dependence on gas flow rate in the ranges considered. It is clear that much longer times are necessary for the silicone oil than for the glucose syrup. This is in the most part due to the difference in liquid density; that of glucose syrup is $50 \%$ greater than that for silicone oil. Also plotted on the figure are drainage times extracted from initial film thicknesses extracted from Figure 15 and Figure 16. Here the 
time is corrected for the transit time for a slug to pass the length of the aerated column of liquid. The vertical extents of the lines are not significant.

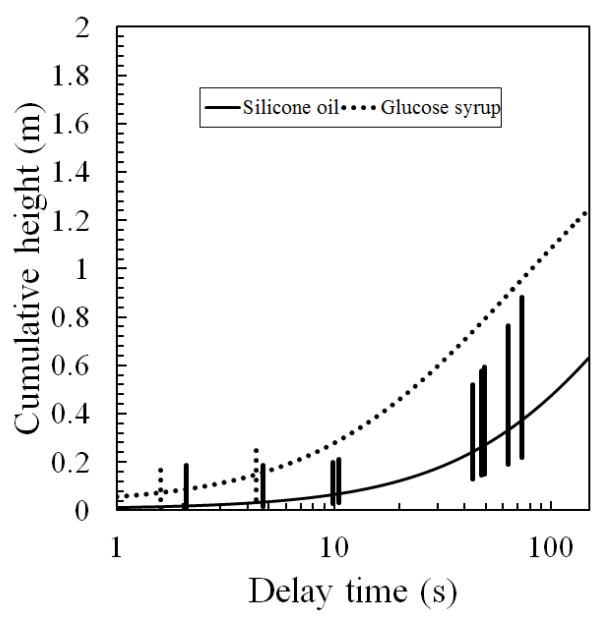

Figure 18: Time dependence for the growth of the height of pool of liquid at the bottom of the column. In both cases column diameter $=240 \mathrm{~mm}$. Silicone oil: gas superficial velocity $=0.223 \mathrm{~m} / \mathrm{s}$; glucose syrup: gas superficial velocity $=0.675 \mathrm{~m} / \mathrm{s}$.

If the mean void fraction in the churn flow portions can be assumed to apply over the entire height of the aerated column, then the expanded height will be $\sim 4 \mathrm{~m}$. This is supported by the pressure output from pressure transducer 3 positioned at $4.17 \mathrm{~m}$ (see Figure 10) which indicates atmospheric pressure. The top surface will then be lifted above this height when a slug/Taylor bubble passes.

From the observations and measurements reported above, it appears that the formation of churn flow is initiated by flooding of the draining film of the walls of the column, particularly when there is a continuous gas core. The flooding process is known to hold up waves but not always successfully and hence the up and down churning motion. This churning flow can be seen in the ECT output and can be inferred from the wall pressure data. At gas velocities just above transition this churning cannot be maintained and the liquid collapses to the bottom of the column to form a liquid slug. The gas builds up underneath it and pushes the slug up until it loses all its liquid by drainage down the Taylor bubble and the residual thin liquid layer 
bursts. The passage of the slug can be seen in the output of the ECT and all three pressure transducers. The higher the gas superficial velocity, the longer churn flow can persist. Attempts have been made to calculate the critical gas velocity for the occurrence of flooding using the equations of McQuillan et al. (1985) and Zapke and Kröger (2000). Though these are presented in terms of dimensionless groups, e.g., Froude, Bond/Eötvös, Ohnesorge numbers, they can be reduced to the form: $\Pi\left(x_{i}^{n_{i}}\right)$, where $x_{i}$ is the variable and $n_{i}$ is the power to which it is raised. These powers are remarkably similar $-0.22 /-0.2$ for liquid superficial velocity, $0.78 / 0.75$ for pipe diameter, $0.345 / 0.65$ for liquid density and $-0.18 /-0.15$ for liquid viscosity. These gave gas velocities larger than those at which the transition to churn flow was observed. Examination of the paper of McQuillan and Whalley (1985) shows that they introduced the effect of liquid viscosity via a term $\left(1+\eta / \eta_{w}\right)^{n}$. For viscosities $>0.1 \mathrm{~Pa}$ s this can be expressed as $\mathrm{K} \eta_{l}^{n}$ and the resulting differences are $<1 \%$. However, it is noted that the equations are empirical correlations which should only be used for interpolation. The current liquid viscosity is two orders of magnitude larger than the largest values employed in the data base used in derivation of the equations. In most work on flooding the thickness of the liquid film is much less than the pipe diameter and so the core velocity is well approximated by the gas superficial velocity. In contrast in the present experiments, because of the thicker films, the core velocity can be twice to five times the gas superficial velocity.

\section{Conclusions}

From the above, it can be concluded that:

1. Three flow patterns can be identified in the experiments reported. At the lowest gas flow rate the pattern is bubbly. However, these bubbles are fewer and larger than found with lower viscosity liquids. As the gas flow rate is increased, the flow is clearly in slug flow with characteristic Taylor bubbles interspersed with liquid slugs. At even higher 
gas velocities there is a transition region, a combination of alternating slug and churn flows. These have different mean void fractions and structure velocities.

2. The bubble velocities for bubbly flow are well predicted by a modified form of the equation proposed by Allahwala and Potter (1979). Those for the slug flow pattern are well predicted by a two-part equation, (4.1). However, as there is no clear method to predict $C_{0}$, this parameter was fitted to the data by linear regression. A value of $C_{0}=$ 3.45 was obtained which lies between those proposed by Collins et al. (1978) and Guet et al. (2004). Beyond the transition velocity, velocities lie below the straight line of (4.7). When data for those portions of time traces that are clearly is churn flow are considered, they are even further below the line.

3. The dominant frequencies for these flows were seen to at first rise with increasing gas superficial velocity in the bubbly flow region, i.e., more bubbles are being formed. In the slug flow region, frequency first falls with increasing gas superficial velocity evidence of coalescence between Taylor bubbles. The frequency then reaches a steady value.

4. The transition to churn flow occurs because of flooding of the film around Taylor bubbles, particularly when a Taylor bubble fills the entire column and the preceding liquid slug burst at the top leaving a continuous gas core. It is characterised by up and down movement of very large waves. This wavy arrangement occasionally breaks down, liquid falls to the bottom to form a slug and the gas collected under it forms a Taylor bubble which pushes it to the top of the column where it bursts. The cycle then starts again.

6. Acknowledgment

This work is part of the NERC grants (Universities of Nottingham/Bristol) NE/G015678/1; NE/G016593/1, EPSRC Programme Grant MEMPHIS, EPSRC EP/K003976/1 and Fond National Suisse grants FNSF 200021-122268 and 200021_162439. Shara K. Mohammed is supported by Kurdistan Regional Government in Iraq. 
7. List of Symbols

$\begin{array}{lll}\text { Symbol } & \text { Description } & \text { Unit } \\ \mathrm{C}_{\mathrm{d}^{*}} & \text { Average drag coefficient } & \\ \mathrm{C}_{\mathrm{o}} & \text { Distribution coefficient } & \\ \mathrm{D} & \text { Pipe diameter } & \mathrm{m} \\ \mathrm{E}_{\mathrm{o}} & \text { Eötvös number } & \\ \mathrm{f}_{\mathrm{n}} & \text { Average frequency } & \mathrm{s}^{-} \\ \mathrm{F}_{\mathrm{r}} & \text { Froude number } & \mathrm{m} / \mathrm{s}^{2} \\ \mathrm{~g} & \text { Gravitational acceleration } & \mathrm{m} \\ \mathrm{L}_{\mathrm{s}} & \text { Liquid slug length } & \mathrm{m} \\ \mathrm{L}_{\mathrm{TB}} & \text { Taylor bubble length } & \mathrm{m} \\ \mathrm{L}_{\mathrm{u}} & \text { Unit slug length } & \mathrm{m} \\ \mathrm{L}_{\mathrm{x}} & \text { Height of the gas-liquid mixture } & \mathrm{m} \\ \mathrm{L}_{0} & \text { Initial height of the liquid } & \\ \mathrm{Re}_{\mathrm{b}} & \text { Buoyancy Reynolds number } & \mathrm{m} / \mathrm{s} \\ \mathrm{U}_{\mathrm{b}} & \text { Rise velocity of Taylor bubble } & \mathrm{m} / \mathrm{s} \\ \mathrm{U}_{\mathrm{st}} & \text { Structure velocity } & \mathrm{m} / \mathrm{s} \\ \mathrm{u}_{\mathrm{f}} & \text { Liquid film velocity } & \mathrm{m} / \mathrm{s} \\ \mathrm{u}_{\mathrm{gs}} & \text { Gas superficial velocity } & \mathrm{m} / \mathrm{s} \\ \mathrm{u}_{\mathrm{ls}} & \text { Liquid superficial velocity } & \mathrm{m} / \mathrm{s} \\ \mathrm{u}_{\mathrm{d}} & \text { Draft velocity } & \end{array}$

\section{Greek Symbols}

$\delta \quad$ Film thickness

$\mathrm{m}$

$\varepsilon_{\mathrm{g}} \quad$ Mean void fraction

$\varepsilon_{\mathrm{gTB}} \quad$ Void fraction in Taylor bubble

$\varepsilon_{\mathrm{gs}} \quad$ Void fraction in liquid slug

$\mu_{1} \quad$ Liquid dynamic viscosity

Gas density

Pa.s

Liquid density

Surface tension of the liquid

$\mathrm{Kg} / \mathrm{m} 3$

$\mathrm{Kg} / \mathrm{m} 3$

Abbreviations

$\mathrm{N} / \mathrm{m}$

ECT Electrical Capacitance Tomography

PDF Probability Density Function

PSD Power Spectrum density

\section{REFERENCES}

ALLAHWALA, S. A. \& POTTER, O. E. 1979. Rise velocity equation for isolated bubbles and for isolated slugs in fluidized beds. Industrial \& Engineering Chemistry Fundamentals, 18, 112-116.

AZZOPARDI, B., PIOLI, L. \& ABDULKAREEM, L. 2014. The properties of large bubbles rising in very viscous liquids in vertical columns. International Journal of Multiphase Flow. 
AZZOPARDI, B. J. 2006. Gas-liquid flows, New York, Begell House.

BENJAMIN, T. B. 1957. Wave formation in laminar flow down an inclined plane. Journal of Fluid Mechanics, 2, 554-573.

BIRD, J. C., DE RUITER, R., COURBIN, L. \& STONE, H. A. 2010. Daughter bubble cascades produced by folding of ruptured thin films. Nature, 465, 759.

BYARS, M. Developments in electrical capacitance tomography. 2nd World Congress on Industrial Process Tomography, Hannover, 2001.

CHIRINOS, M., GONZALEZ, J. \& LAYRISSE, I. 1983. Rheological properties of crude oils from the Orinoco Oil Belt and their mixtures with diluents. Revista Tecnica Intevep, 3, 103115.

CLANET, C., HÉRAUD, P. \& SEARBY, G. 2004. On the motion of bubbles in vertical tubes of arbitrary cross-sections: some complements to the Dumitrescu-Taylor problem. Journal of Fluid Mechanics, 519, 359-376.

COLLINS, R., DE MORAES, F., DAVIDSON, J. \& HARRISON, D. 1978. The motion of a large gas bubble rising through liquid flowing in a tube. Journal of Fluid Mechanics, 89, 497514.

COSTIGAN, G. \& WHALLEY, P. 1997. Slug flow regime identification from dynamic void fraction measurements in vertical air-water flows. International Journal of Multiphase Flow, 23, 263-282.

DAVIES, R. \& TAYLOR, G. 1950. The mechanics of large bubbles rising through extended liquids and through liquids in tubes. Proceedings of the Royal Society of London. Series A. Mathematical and Physical Sciences, 200, 375-390.

DUKLER, A. \& FABRE, J. 1994. GAS-LIQUID SLUG FLOW. Multiphase science and technology, 8.

DUMITRESCU, D. T. 1943. Strömung an einer Luftblase im senkrechten Rohr. ZAMM-Journal of Applied Mathematics and Mechanics/Zeitschrift für Angewandte Mathematik und Mechanik, 23, 139-149.

FABRE, J. \& LINÉ, A. 1992. Modeling of two-phase slug flow. Annual Review of Fluid Mechanics, 24, 21-46.

GADDIS, E. \& VOGELPOHL, A. 1986. Bubble formation in quiescent liquids under constant flow conditions. Chemical Engineering Science, 41, 97-105.

GARDNER, J. E., KETCHAM, R. A. \& MOORE, G. 2013. Surface tension of hydrous silicate melts: Constraints on the impact of melt composition. Journal of Volcanology and Geothermal Research, 267, 68-74.

GIORDANO, D., RUSSELL, J. K. \& DINGWELL, D. B. 2008. Viscosity of magmatic liquids: a model. Earth and Planetary Science Letters, 271, 123-134.

GOVAN, A., HEWITT, G., RICHTER, H. \& SCOTT, A. 1991. Flooding and churn flow in vertical pipes. International journal of multiphase flow, 17, 27-44.

GUET, S., OOMS, G., OLIEMANS, R. \& MUDDE, R. 2004. Bubble size effect on low liquid input drift-flux parameters. Chemical engineering science, 59, 3315-3329.

IBRAHIM, A., HEWAKANDAMBY, B., YANG, Z. \& AZZOPARDI, B. Effect of Liquid Viscosity on Two-Phase Flow Development in a Vertical Large Diameter Pipe. ASME 2018 5th Joint US-European Fluids Engineering Division Summer Meeting, 2018. American Society of Mechanical Engineers, V003T19A011-V003T19A011.

KAJI, R., HILLS, J. H. \& AZZOPARDI, B. J. 2009. Extracting information from time series data in vertical upflow. Multiphase Science and Technology, 21. 
KHATIB, Z. \& RICHARDSON, J. 1984. Vertical co-current flow of air and shear thinning suspensions of kaolin. Chemical engineering research and design, 62, 139-154.

KUNCOVÁ, G. \& ZAHRADNÍK, J. 1995. Gas holdup and bubble frequency in a bubble column reactor containing viscous saccharose solutions. Chemical Engineering and Processing: Process Intensification, 34, 25-34.

LLEWELLIN, E., DEL BELLO, E., TADDEUCCI, J., SCARLATO, P. \& LANE, S. 2012. The thickness of the falling film of liquid around a Taylor bubble. Proceedings of the Royal Society A: Mathematical, Physical and Engineering Science, 468, 1041-1064.

LUO, W., LIANG, W., ZHANG, G. \& WANG, J. 2004. Fluidization characteristics of silicon particles with a wide size distribution. Chinese Journal of Chemical Engineering, 12, 851-856.

MAKKAWI, Y. \& WRIGHT, P. 2002. Fluidization regimes in a conventional fluidized bed characterized by means of electrical capacitance tomography. Chemical Engineering Science, 57, 2411-2437.

MCQUILLAN, K. \& WHALLEY, P. 1985. A comparison between flooding correlations and experimental flooding data for gas-liquid flow in vertical circular tubes. Chemical engineering science, 40, 1425-1439.

MCQUILLAN, K., WHALLEY, P. \& HEWITT, G. 1985. Flooding in vertical two-phase flow. International Journal of Multiphase Flow, 11, 741-760.

MEZA, C. E. \& BALAKOTAIAH, V. 2008. Modeling and experimental studies of large amplitude waves on vertically falling films. Chemical Engineering Science, 63, 47044734.

Mohammed, S.K., 2017. Gas-high viscosity oil flow in vertical large diameter pipes (Doctoral dissertation, University of Nottingham).

MOHAMMED, S. K., HASAN, A., DIMITRAKIS, G. \& AZZOPARDI, B. J. 2018. Churn flow in high viscosity oils and large diameter columns. International Journal of Multiphase Flow, 100, 16-29.

MORI, K., KAJI, M., INOUE, K., NAKAZATOMI, M., SHIMIZU, H., KONDO, Y. \& SEKOGUCHI, K. 1996. Study on Wave Venation in Gas-Liquid Two-Phase Flow (3rd Report, Distinction between Huge waves and Disturbance Waves and Characteris-tics of Huge Waves). Trans. Jpn. Soc. Mech. Eng.,(in Japanese), 62, 3149-3156.

NICKLIN, D. 1962. Two-phase bubble flow. Chemical engineering science, 17, 693-702.

NUSSELT, W. 1916. Die Oberflachenkondesation des Wasserdamffes the surface condensation of water. Zetrschr. Ver. Deutch. Ing., 60, 541-546.

OLOUGHLIN, J. R. 1965. Liquid film drain from an accelerating tank wall. AIAA Journal, 3, 158-158.

PANDIT, A., PHILIP, J., DAVIDSON, J. \& DODD, P. The generation of small bubbles in liquids. International Chemical Reaction Engineering Conference, 1987. 72-82.

PAPANASTASIOU, T., GEORGIOU, G. \& ALEXANDROU, A. N. 1999. Viscous fluid flow, CRC Press.

PHILIP, J., PROCTOR, J., NIRANJAN, K. \& DAVIDSON, J. 1990. Gas hold-up and liquid circulation in internal loop reactors containing highly viscous Newtonian and nonNewtonian liquids. chemical Engineering science, 45, 651-664.

QIU, G., YE, J., WANG, H. \& YANG, W. 2014. Investigation of flow hydrodynamics and regime transition in a gas-solids fluidized bed with different riser diameters. Chemical Engineering Science, 116, 195-207. 
RANA, B. K., DAS, A. K. \& DAS, P. K. 2015. Mechanism of bursting Taylor bubbles at free surfaces. Langmuir, 31, 9870-9881.

SAAYMAN, J., NICOL, W., VAN OMMEN, J. R. \& MUDDE, R. F. 2013. Fast X-ray tomography for the quantification of the bubbling-, turbulent-and fast fluidization-flow regimes and void structures. Chemical engineering journal, 234, 437-447.

SHAH, Y., KELKAR, B. G., GODBOLE, S. \& DECKWER, W. D. 1982. Design parameters estimations for bubble column reactors. AIChE Journal, 28, 353-379.

SHARAF, S., VAN DER MEULEN, G. P., AGUNLEJIKA, E. O. \& AZZOPARDI, B. J. 2016. Structures in gas-liquid churn flow in a large diameter vertical pipe. International Journal of Multiphase Flow, 78, 88-103.

SHU, W. 1984. A viscosity correlation for mixtures of heavy oil, bitumen, and petroleum fractions. Society of Petroleum Engineers Journal, 24, 277-282.

VAN ROSSUM, J. 1958. Viscous lifting and drainage of liquids. Applied Scientific Research, Section $A, 7,121-144$.

VIANA, F., PARDO, R., YANEZ, R., TRALLERO, J. L. \& JOSEPH, D. D. 2003. Universal correlation for the rise velocity of long gas bubbles in round pipes. Journal of Fluid Mechanics, 494.

ZAPKE, A. \& KRÖGER, D. 2000. Countercurrent gas-liquid flow in inclined and vertical ducts-I: Flow patterns, pressure drop characteristics and flooding. International journal of multiphase flow, 26, 1439-1455.

ZUBER, N. \& FINDLAY, J. 1965. Average volumetric concentration in two-phase flow systems. Journal of heat transfer, 87, 453-468. 